\title{
Supply Contract Design for Competing Heterogeneous Suppliers under Asymmetric Information*
}

\author{
Zhaolin $\mathrm{Li}^{\dagger}$ \\ erick.li@sydney.edu.au \\ Discipline of Business Analytics \\ The University of Sydney \\ Jennifer K. Ryan ${ }^{\ddagger}$ \\ ryanj60rpi.edu \\ Department of Industrial \& Systems Engineering \\ Rensselaer Polytechnic Institute \\ Lusheng Shao ${ }^{\S}$ \\ lusheng. shao@unimelb.edu .au \\ Department of Management and Marketing \\ The University of Melbourne \\ Daewon Sun \\ dsun@nd.edu \\ Department of Management \\ University of Notre Dame
}

*Author names are listed alphabetically and all authors contributed equally.

${ }^{\dagger}$ Mailing Address: Zhaolin Li, Discipline of Business Analytics, The University of Sydney Business School, NSW 2006, Australia.

${ }^{\ddagger}$ Mailing Address: Jennifer K. Ryan, ISE, RPI, 110 8th St., CII, Suite 5015, Troy, NY 12180; Telephone: 518-276-6486; Fax: 518-276-8227.

$\S$ Mailing Address: Lusheng Shao, Department of Management and Marketing, Faculty of Business and Economics, The University of Melbourne, VIC 3010, Australia.

`Mailing Address: Daewon Sun, Room 359, Mendoza CoB, Notre Dame, IN 46556; Telephone: 574-631-0982; Fax: 574-631-5127. 


\title{
Supply Contract Design for Competing Heterogeneous Suppliers under Asymmetric Information
}

\begin{abstract}
This paper considers a supply chain with two heterogeneous suppliers and a common retailer whose type is either low-volume or high-volume. The retailer's type is unknown to the suppliers. The flexible supplier has a high variable cost and a low fixed cost, while the efficient supplier has a low variable cost and a high fixed cost. Each supplier offers the retailer a menu of contracts. The retailer chooses the contract that maximizes its expected profit. For this setting, we characterize the equilibrium contract menus offered by the suppliers to the retailer. We find that the equilibrium contract menus depend on which supplier-retailer match can generate the highest supply chain profit and on how much information rent the supplier may need to pay. An important feature of the equilibrium contract menus is that the contract assigned to the more profitable retailer will coordinate the supply chain, while the contract assigned to the less profitable retailer may not. In addition, in some circumstances, the flexible supplier may choose not to serve the high-volume retailer, in order to avoid excessive information rent.
\end{abstract}

Keywords: Supply chain management, Supply contracts, Competition, Asymmetric Information, Stochastic inventory model

Received: September 2012; accepted: July 2014 by Albert Ha after four revisions. 


\section{Introduction}

The theory of mechanism design has been successfully applied in a variety of supply chain contexts in which one supply chain entity possesses private information, which another entity attempts to elicit by offering a menu of contracts. In practice, that private information may be the buyer's demand volume or cost structure, which are often unobservable to the supplier(s). For example, as Babich et al. (2012) note, a buyer will often possess more accurate information on the market demand because she is closer to the customer and, in some cases, has direct access to consumers.

In this paper, we study a supply chain with two heterogeneous suppliers and one retailer. Each of the suppliers will design contract menus which they will offer to the retailer. The retailer, who is endowed with private information regarding the external demand, will select just one of the contracts. The retailer may be either high- or low-volume, where the demand distribution of the low-volume retailer is stochastically smaller than that of the high-volume retailer. The retailer's operation is captured by a newsvendor model with lost sales.

Our analysis of this model fills several gaps in the literature. In practice, procurement often involves multiple competing heterogeneous suppliers (Chen-Ritzo et al., 2005). However, the effect of competition between heterogeneous suppliers on the optimal contract menu under asymmetric information has not been thoroughly studied, i.e., the literature generally considers a monopoly supplier who faces a retailer of unknown type. When there is a single supplier, the retailer's reservation profit, i.e., the profit the retailer can earn from the best outside option, is generally taken to be fixed and known. When there are two competing suppliers, the reservation profit is endogenous to the model, i.e., when evaluating the contract offered by a given supplier, the retailer's reservation profit is the profit offered by the other supplier's contract. To attract a given retailer type, the contract menus must be designed to offer that retailer type her reservation profit. It is thus unclear how competition, with endogenous reservation profits, affects the form of the optimal contract menus offered by the suppliers. For example, should each supplier offer a menu to attract all retailer types or should the supplier limit the menu so as to attract only a subset of retailer types? We answer these questions by considering a model 
of duopoly competition under asymmetric information, with suppliers who differ in their costs.

In our model setting, the competing suppliers offer contract menus to a retailer, who must accept or reject those contracts, i.e., the retailer has no control over the contract design. Such a setting can occur when the suppliers exert power over the buyer (see Shi et al. (2013) and Chen et al. (2014) for a discussion of power relationships in supply chains). There are a number of practical examples of such a setting. For example, consider a small manufacturer of smart phones in China ${ }^{1}$ who must procure mobile processors from manufacturers such as Qualcomm or Mediatek. While a large and established buyer, such as Samsung, may be able to exert power over Qualcomm or Mediatek, these small and relatively new Chinese buyers will not have the same advantage. Similarly, the major computer chip manufacturers, such as Intel and AMD, will possess greater negotiation power over small personal computer assemblers than they do over large customers, such as Lenovo.

In our model, the competing suppliers have different cost structures. Specifically, we consider an efficient supplier (with low variable cost and positive fixed cost) and a flexible supplier (with high variable cost and negligible fixed cost). As discussed in Fox et al. (2006), there are various practical settings in which this may occur. For example, in a manufacturing environment, the cost structure is often dictated by the nature of the equipment used by the suppliers. Highly automated, capital intensive manufacturing environments tend to have a high fixed cost and a low variable cost, due to their limited use of labor. In contrast, less automated processes will have a lower fixed cost, but a higher variable cost, due to the significant labor requirements.

Finally, the existing literature generally assumes that all contracts on the menu are either coordinating contracts, which induce the retailer to order the system optimal quantity and thus maximize the supply chain profit, or uncoordinated contracts, which do not. The possibility of offering a combination of contract types has not been investigated. We relax this assumption and allow the suppliers to offer a combination of contract types. Our model also allows the suppliers to offer just a single contract, designed to attract the retailer whose demand volume

\footnotetext{
${ }^{1}$ There has recently been significant attention paid to the growth of small and moderate sized cell phone manufacturers in China. See, for example, http://www.businessinsider.com/chinese-smartphone-manufacturers2014-2 and http://www.nytimes.com/2009/04/28/technology/28cell.html. Both websites retrieved on July 29, 2014.
} 
most closely matches the supplier's cost structure.

\subsection{Summary of Results and Insights}

For our model setting, we find that the equilibrium contract menus depend critically on the magnitude of the fixed cost of the efficient supplier. While the efficient supplier has an advantage due to his lower variable cost, if the fixed cost is sufficiently large, the flexible supplier may provide the lowest overall cost, particularly for a low-volume retailer. Thus, as the fixed cost increases, the flexible supplier gains competitive advantage over the efficient supplier, which affects the optimal contract design. As the efficient supplier's fixed cost increases, the flexible supplier progresses through the following stages: (i) not serving either retailer type, (ii) serving only the low-volume retailer, with whom the flexible supplier has a cost advantage, leaving the efficient supplier to serve the high volume retailer, (iii) serving both retailer types and allowing the low-volume retailer to earn a profit in excess of its reservation profit (iv) serving both retailer types and allowing both retailer types to earn only their reservation profit, and (v) acting as a monopolist.

Our analysis also enables us to characterize the conditions under which it is optimal for a supplier to serve both retailer types, as opposed to selectively serving the retailer type whose volume most closely matches the supplier's cost structure. Intuitively, one might expect that a dominating supplier, i.e., one who has a cost advantage for both retailer types, should always serve both retailer types. However, our results indicate that, in some circumstances, a dominating flexible supplier should choose not to serve the high-volume retailer, and should instead focus on winning the low-volume retailer, whose demand volume most closely matches the flexible supplier's cost structure. By doing so, the flexible supplier can avoid paying information rent (additional profit beyond the retailer's reservation profit) to the high-volume retailer.

Finally, while the efficient supplier's contracts always induce the retailer to order the system optimal quantity, the same is not true for the flexible supplier's contracts. In some cases, offering a combination of contract types, i.e., one that induces (does not induce) the low-volume (highvolume) retailer to order the system optimal order quantity, can enable the flexible supplier to 
serve both retailer types, while maximizing his profit. The flexible supplier's trade-off in this situation is between reducing information rent (by using a combination of contract types) and improving the supply chain profit (by using only contracts that coordinate the order quantity).

\section{Literature Review}

Our study is related to the supply chain literature that considers a supplier's contracting decision by applying the theory of optimal contract menus. See Kouvelis et al. (2006) for a comprehensive review of the early literature. Although there are numerous papers in the supply chain literature that examine a buyer's optimal contract menu, we do not include these articles in our survey because our focus is on the supply side, rather than the demand side. Numerous articles have investigated a supplier's optimal contract menu when the buyer possesses private information regarding the downstream demand, e.g., Cachon and Lariviere (2001), Ozer and Wei (2006), Burnetas et al. (2007) and Gan et al. (2010). In this context, to induce the buyer reveal its private demand information, the supplier must offer information rent to the buyer. In some specific contexts, the supplier is able to avoid information rent by using a two-part tariff type of contracts, e.g., Akan et al. (2011), Babich et al. (2012) and Dai et al. (2012). In addition to private demand information, the existing literature also considers that the buyer may incur an extra cost to process the procured component, e.g., Ha (2001) and Corbett et al. (2004), or to store the procured product, e.g., Corbett and Groote (2000), and that the buyer may exert some private effort to increase sales, e.g., Mukhopadhyay et al. (2009).

The papers mentioned above do not consider competition amongst suppliers. In contrast, Ozer and Raz (2011) study a supply chain with two heterogeneous suppliers and one buyer. The objective of the big supplier (with low variable cost) is to win the business of the buyer over a competing small supplier, whose (higher) variable cost may be private. The authors find that, while the buyer benefits when the small supplier's variable cost is known, the big supplier may be better off with asymmetric information regarding that cost. While Ozer and Raz (2011) assume that the big supplier has incomplete information regarding the small supplier's production cost, we assume that both suppliers have incomplete information regarding the buyer's volume, and 
we find that complete information is always beneficial to the suppliers. In addition, since the big supplier is assumed to have a cost advantage over the small supplier, Ozer and Raz (2011) find that the buyer always chooses to work with the big supplier. In contrast, we introduce a fixed cost for the big supplier, which ensures that neither supplier has a cost advantage for all volumes. We find that which supplier is selected by the buyer depends on the buyer's volume.

Cachon and Kök (2010) study a supply chain setting in which two suppliers compete to sell partially substitutable products to a common retailer, under the assumption of symmetric demand information. The authors' focus is on how different contract forms (i.e., wholesale price, two-part tariff and quantity discount contracts) affect the competition dynamics between the competing suppliers. Contrary to the findings without competition, the authors demonstrate that the more sophisticated contract forms (i.e., the two-part tariff and quantity discount contracts) may intensify the competition between the suppliers and thus may make the suppliers worse off. Lee and Yang (2013) extend Cachon and Kök (2010) by incorporating asymmetric demand information into the model. Their main result is that the suppliers prefer the two-part tariff contract to the quantity discount contract.

Our paper differs from Cachon and Kök (2010) and Lee and Yang (2013) in several ways. In terms of the model, we consider a newsvendor buyer who purchases a homogenous product from two competing suppliers. Our model also allows for a generic contract form which covers the contract forms considered in the previous papers as special cases. In addition, we endogenize the supplier's decision regarding which type(s) of the buyer to serve. This decision is irrelevant in Lee and Yang (2013) due to the fact that, in their setting with partial substitutes, it is optimal for each supplier to serve all buyer types. Given these differences, our model leads to contrasting results. Specifically, we find that, in some cases, a flexible supplier who possesses a cost advantage for both buyer types may choose not to serve the high-volume buyer, i.e., the supplier chooses to serve only the low-volume buyer, whose volume more closely matches the supplier's cost structure. By doing so, the flexible supplier can avoid paying information rent to the high-volume buyer. Thus, as will be seen, our research highlights how the suppliers' contract design decisions under competition must trade-off information rent and cost advantage. 


\section{Problem Description and Model Formulation}

We consider a supply chain with two heterogeneous suppliers (suppliers 1 and 2) and one retailer. The suppliers differ in their costs and compete for an order to be placed by the retailer. Only one supplier will be selected by the retailer. Supplier 1 (the flexible supplier) incurs a small fixed cost, which we normalize to zero, and a variable cost, $c_{1}$. Supplier 2 (the efficient supplier) incurs a large fixed cost, $F$, and a low variable cost $c_{2}$, with $c_{2} \leq c_{1}$. The fixed cost $F$ is incurred only if the retailer orders a positive quantity. Thus, if we let $q$ denote the retailer's order quantity, the cost functions for suppliers 1 and 2 are $c_{1}(q)=c_{1} q$ and $c_{2}(q)=c_{2} q+F$ for $q>0$, with $c_{2}(q)=0$ for $q=0$. Because they are participants in the same industry and understand the relevant technology and business environment, the suppliers are assumed to know each other's cost structure. We use the subscripts $i, j \in\{1,2\}$ to denote the suppliers.

The retailer is endowed with private information regarding the external demand volume. This assumption reflects the fact that the retailer is closer to the market than the suppliers. With probability $\delta$, the retailer is low-volume (type- $L$ ) with external demand $D_{L}$, which has probability density function (pdf) $g_{L}(\cdot)$ and cumulative distribution function (CDF) $G_{L}(\cdot)$. With probability $1-\delta$, the retailer is high-volume (type- $H$ ) with external demand $D_{H}$. We assume that $D_{H}$ is equal in distribution to $\beta D_{L}$ for some constant $\beta>1$. In other words, the random variable $D_{H}$ has $\operatorname{CDF} G_{H}(d)=G_{L}\left(\frac{d}{\beta}\right)$ for all $d \geq 0$. This assumption has been used in several prior studies (e.g., Cachon and Lariviere, 2001; Akan et al., 2011). For instance, if $D_{L}$ follows Uniform distribution on the interval $[0, a]$, then $D_{H}$ follows Uniform distribution on the interval $[0, \beta a]$. We use the subscripts $\theta, \theta^{\prime} \in\{L, H\}$ to denote the retailer types.

The retail price of the product is $r$, which is exogenously specified. We consider the lostsales model for the retailer. Thus, if a type- $\theta$ retailer chooses supplier $i$ and orders $q$ units of inventory, the total supply chain profit is $r \min \left(q, D_{\theta}\right)-c_{i}(q)$. We assume that the distribution of the stochastic demand and the distribution of retailer types are known to the suppliers.

Finally, the sequence of events and decisions in our model is shown in Figure 1. 


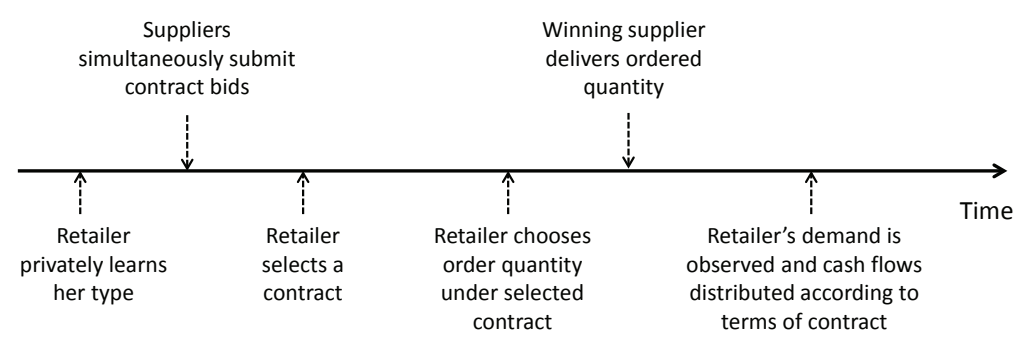

Figure 1: Sequence of events and decisions

\subsection{The Suppliers' Contract Design Problem}

Each supplier bids a menu of contracts, with up to two contracts in each menu. Let contract-i $\theta$ be the contract bid by supplier $i$ intended to attract the type- $\theta$ retailer. This contract can be represented by a generic bivariate function $m_{i \theta}(q, D)$, which represents the profit earned by supplier $i$ under the contract, given that the retailer orders $q$ units and the realized demand is $D$. In other words, if the retailer orders $q$ units from supplier $i$ and the demand is $D$, the retailer must make a payment of $m_{i \theta}(q, D)+c_{i}(q)$ to supplier $i$. We refer to $m_{i \theta}(q, D)$ as the markup function. We assume $m_{i \theta}(0, D)=0$ for any $D$. By specifying the function $m_{i \theta}(q, D)$, we can replicate the cash flows generated by various supply chain contracts. For example:

- The supplier can bid a two-part tariff buy-back contract with a fixed charge $K_{i \theta}$, wholesale price $w_{i \theta}$ per unit, and buy-back rate $b_{i \theta}$ per unit. In this case, $m_{i \theta}(q, D)=w_{i \theta} q-c_{i}(q)+$ $K_{i \theta}-b_{i \theta}(q-D)^{+}$. If $K_{i \theta}=b_{i \theta}=0$, the contract reduces to a wholesale-price contract.

- The supplier can bid a quantity-inflexible contract, with markup function $m_{i \theta}(q, D)=m_{i \theta}$ if $q=q_{i \theta}$, and $m_{i \theta}(q, D)=\infty$ if $q \neq q_{i \theta}$. Thus, if the retailer accepts contract-i $\theta$, she must order the specified amount, $q_{i \theta}$. The quantity-inflexible contract is denoted by $\left(q_{i \theta}, m_{i \theta}\right)$.

Let $T_{i \theta}(q)=r E\left[\min \left(q, D_{\theta}\right)\right]-c_{i}(q)$ denote the expected total supply chain profit when the type- $\theta$ retailer selects supplier $i$. The type- $\theta^{\prime}$ retailer's profit if she accepts contract- $i \theta$ is $T_{i \theta^{\prime}}(q)-E\left[m_{i \theta}\left(q, D_{\theta^{\prime}}\right)\right]$. Finally, let $\hat{q}_{(i \theta) \theta^{\prime}}=\arg \sup _{q \geq 0}\left\{T_{i \theta^{\prime}}(q)-E\left[m_{i \theta}\left(q, D_{\theta^{\prime}}\right)\right]\right\}$ be the order quantity that maximizes the type- $\theta^{\prime}$ retailer's profit if she accepts contract- $i \theta$. For simplicity, let $\hat{q}_{i \theta}=\hat{q}_{(i \theta) \theta}$ to be the optimal order quantity for the type- $\theta$ retailer when she chooses contract- $i \theta$.

We next present our formulation of supplier $i$ 's contract design problem. In formulating this problem, it is necessary to introduce indicator variables $\alpha_{i \theta}$ such that $\alpha_{i \theta}=1$ if $\hat{q}_{(i \theta) \theta^{\prime}}>0$ for all $\theta^{\prime}$ and $\alpha_{i \theta}=0$ if $\hat{q}_{(i \theta) \theta^{\prime}}=0$ for all $\theta^{\prime}$. In other words, if $\alpha_{i \theta}=0$, contract- $i \theta$ is designed to 
discourage either retailer type from participating. For example, the markup function could be $m_{i \theta}(q, D)=\infty$ if $q>0$ and $m_{i \theta}(0, D)=0$ for any $D$. When $\alpha_{i \theta}=0$, we say that contract- $i \theta$ is a dummy contract; whereas when $\alpha_{i \theta}=1$, we say that contract- $i \theta$ is a distinctive contract. As explained in the online supplement, these indicator variables are needed to model the fact that a supplier may choose to offer only a single contract to attract a single retailer type.

In summary, supplier $i$ 's contract menu can be described by two markup functions, $m_{i \theta}$ and $m_{i \theta^{\prime}}$, and two indicator variables, $\alpha_{i \theta}$ and $\alpha_{i \theta^{\prime}}$. The objective function of supplier $i$ is:

$$
V_{i}=\max _{\alpha_{i \theta}, m_{i \theta}}\left\{\delta \alpha_{i L} E\left[m_{i L}\left(\hat{q}_{i L}, D_{L}\right)\right]+(1-\delta) \alpha_{i H} E\left[m_{i H}\left(\hat{q}_{i H}, D_{H}\right)\right]\right\}
$$

which is subject to the following constraints:

$$
\begin{aligned}
& \sup _{q \geq 0}\left\{T_{i \theta}(q)-E\left[m_{i \theta}\left(q, D_{\theta}\right)\right]\right\} \geq \sup _{q \geq 0}\left\{T_{i \theta}(q)-E\left[m_{i \theta^{\prime}}\left(q, D_{\theta}\right)\right]\right\}, \\
& \sup _{q \geq 0}\left\{T_{i \theta}(q)-E\left[m_{i \theta}\left(q, D_{\theta}\right)\right]\right\} \geq \alpha_{i \theta} \alpha_{j \theta} \cdot \sup _{q \geq 0}\left\{T_{j \theta}(q)-E\left[m_{j \theta}\left(q, D_{\theta}\right)\right]\right\}, \\
& \sup _{q \geq 0}\left\{T_{i \theta}(q)-E\left[m_{i \theta}\left(q, D_{\theta}\right)\right]\right\} \geq \alpha_{i \theta} \alpha_{j \theta^{\prime}} \cdot \sup _{q \geq 0}\left\{T_{j \theta}(q)-E\left[m_{j \theta^{\prime}}\left(q, D_{\theta}\right)\right]\right\},
\end{aligned}
$$

for $\theta, \theta^{\prime} \in\{H, L\}, \theta \neq \theta^{\prime}$ and $i, j \in\{1,2\}, i \neq j$.

According to Lee and Yang (2013), by the revelation principle, once supplier $j$ 's contract offer is fixed, it is sufficient for supplier $i$ to consider only truth-revealing contracts, i.e., those contracts that induce the retailer to choose the contract intended for her true state. Thus, we have constraint (IC), which ensures that the type- $\theta$ retailer chooses contract- $i \theta$ over contract- $i \theta^{\prime}$, and that the induced order quantity for the type- $\theta$ retailer will be $\hat{q}_{i \theta}$. We refer to constraint (IC) as the within-menu incentive compatibility constraint. The modifier "within-menu" emphasizes that type- $\theta$ retailer compares the two contracts offered by supplier $i$ and selects the preferred one. Note that contract- $i \theta$ may not be the type- $\theta$ retailer's final choice because the type- $\theta$ retailer also evaluates the contracts on supplier $j$ 's menu.

Constraints (IR1) and (IR2) are the between-menu individual rationality constraints for supplier $i$ 's contract design problem. These constraints ensure that the type- $\theta$ retailer chooses sup- 
plier $i$ 's contract over supplier $j$ 's contract. The modifier "between-menu" emphasizes that the type- $\theta$ retailer must compare the preferred contract from supplier $i$ 's menu with the contracts on supplier $j$ 's menu. Thus, the profit earned by accepting either of supplier $j$ 's contracts, i.e., the right hand side (RHS) of constraints (IR1) and (IR2), becomes the endogenous reservation profit for the type- $\theta$ retailer when evaluating contract- $i \theta$ offered by supplier $i$.

Given (IC), the retailer will truthfully report her type to supplier $i$, i.e., will choose the contract designed by supplier $i$ for her type. However, when designing his contracts, supplier $i$ cannot assume that the retailer will truthfully report to supplier $j$. Hence, for each retailer type we have two IR constraints: (IR1) if the retailer truthfully reports to supplier $j$, and (IR2) if the retailer does not truthfully report to supplier $j$. If either supplier chooses not to compete for the business of the type- $\theta$ retailer, and thus offers that retailer type a dummy contract, the relevant between-menu individual rationality constraint is not necessary and is eliminated through the indicator variables. In the online supplement, we prove this fact in detail and also argue that constraint (IR2) can be eliminated. Thus, supplier $i$ 's contract design problem is to maximize (1), subject to (IC) and (IR1). There are two special cases worth noting:

- Supplier $i$ may choose to exclude the type- $\theta^{\prime}$ retailer by offering a dummy contract which induces $q_{\left(i \theta^{\prime}\right) \theta}=0$ and has $m_{i \theta^{\prime}}(0, D)=0$. This implies $\alpha_{i \theta^{\prime}}=0$ and $\alpha_{i \theta}=1$. In this case, since $T_{i \theta}(0)=T_{i \theta^{\prime}}(0)=0$, constraints (IC) reduce to:

$$
\sup _{q \geq 0}\left\{T_{i \theta}(q)-E\left[m_{i \theta}\left(q, D_{\theta}\right)\right]\right\} \geq 0 \quad \text { and } \quad 0 \geq \sup _{q \geq 0}\left\{T_{i \theta^{\prime}}(q)-E\left[m_{i \theta}\left(q, D_{\theta^{\prime}}\right)\right]\right\}
$$

which ensure that the type- $\theta$ retailer prefers contract- $i \theta$ over the dummy contract- $i \theta^{\prime}$, which provides a maximum profit equal to 0 , while the type- $\theta^{\prime}$ retailer prefers the dummy contract- $i \theta^{\prime}$ over the distinctive contract- $i \theta$.

- The supplier may offer a "one-size-fits-all" contract to attract both types of retailers. To capture this scenario, we simply use identical forms for $m_{i \theta}$ and $m_{i \theta^{\prime}}$, i.e., $m_{i \theta}(q, D)=$ $m_{i \theta^{\prime}}(q, D)$ for all $q$ and $D$, and $\alpha_{i \theta}=\alpha_{i \theta^{\prime}}=1$.

\subsection{The Full-Information Benchmark}

If $\delta=0$ or $\delta=1$, then the retailer's type is known. We call this case the full-information scenario. Because the retailer's type is known, it is optimal for each supplier to offer only one 
contract. For simplicity, we suppress the subscript $\theta$. Supplier $i$ 's problem becomes:

$$
\max _{\alpha_{i}, m_{i}}\left\{\alpha_{i} E\left[m_{i}\left(\hat{q}_{i}, D\right)\right]\right\}
$$

subject to the constraint

$$
\sup _{q \geq 0}\left\{T_{i}(q)-E\left[m_{i}(q, D)\right]\right\} \geq 0
$$

where $T_{i}(q)=r E[\min (q, D)]-c_{i}(q)$, and the between-menu IR constraint

$$
\sup _{q \geq 0}\left\{T_{i}(q)-E\left[m_{i}(q, D)\right]\right\} \geq \alpha_{i} \alpha_{j} \cdot \sup _{q \geq 0}\left\{T_{j}(q)-E\left[m_{j}(q, D)\right]\right\}
$$

Let $\hat{q}_{i}$ denote the retailer's optimal order quantity under contract- $i$. Let $\Pi_{i}=\sup _{q \geq 0}\left\{T_{i}(q)\right\}$ denote the maximum expected total supply chain profit given the retailer sources from supplier $i$, and let $\bar{q}_{i}$ be the maximizer of $T_{i}(q)$. In the full information setting, it is optimal for the supplier to set $\alpha_{i}=1$ because supplier $i$ makes no profit when $\alpha_{i}=0$. We can now characterize the full-information equilibrium. Proofs of the propositions can be found in the appendix.

Proposition 1 The full-information equilibrium has the following characteristics:

a) Contract $i$ bid by supplier $i$ induces the supply chain-optimal order quantity (i.e., $\hat{q}_{i}=\bar{q}_{i}$ ).

b) The expected profit earned by supplier $i$ is $E\left[m_{i}\left(\hat{q}_{i}, D\right)\right]=\left(\Pi_{i}-\Pi_{j}\right)^{+}$.

As introduced in the next section (see Table 1 ), we define a threshold, $F_{1}$, such that, if the retailer is low-volume, the total supply chain profit is higher with the efficient supplier than with the flexible supplier only if $F<F_{1}$. Similarly, we define a threshold $F_{2}$, where $F_{2}>F_{1}$, such that, if the retailer is high-volume, the total supply chain profit is higher with the efficient supplier than with the flexible supplier only if $F<F_{2}$. We then have the following:

- If $F<F_{1}$, the low-volume retailer will contract with supplier 2 and earn $\Pi_{1}$. The supplier will earn $\Pi_{2}-\Pi_{1}$. Otherwise, the low-volume retailer will contract with supplier 1 and earn $\Pi_{2}$. The supplier will earn $\Pi_{1}-\Pi_{2}$.

- If $F<F_{2}$, the high-volume retailer will contract with supplier 2 and earn $\Pi_{1}$. The supplier will earn $\Pi_{2}-\Pi_{1}$. Otherwise, the high-volume retailer will contract with supplier 1 and earn $\Pi_{2}$. The supplier will earn $\Pi_{1}-\Pi_{2}$. 
There are multiple contracts that could lead to this equilibrium outcome. To elaborate, we define $t_{i}(q)=r E\left[\min \left(q, D_{\theta}\right)\right]-c_{i} q$ to be the expected chain profit (excluding any fixed cost) when the retailer selects supplier $i$. The following are possible equilibrium contracts:

- Supplier $i$ can bid a two-part tariff buy-back contract with $w_{i}=c_{i}+\rho\left(r-c_{i}\right), b_{i}=\rho r$, and $K_{i}=\left(\Pi_{i}-\Pi_{j}\right)^{+}+A_{i}-\rho t_{i}\left(\bar{q}_{i}\right)$, where $A_{1}=0, A_{2}=F$ and $0 \leq \rho \leq 1$. Notice that the value of $K_{i}$ can be either positive or negative because $\rho$ is freely chosen between 0 and 1 . It can be verified that $m_{i}(q, D)=\rho\left[r \min (q, D)-c_{i} q\right]-A_{i}+K_{i}$. The retailer's expected profit is $(1-\rho) t_{i}(q)-K_{i}$ when the order quantity is $q$. Since $\frac{r-w_{i}}{r-b_{i}}=\frac{r-c}{r}$, the contract induces the retailer to order the system optimal quantity, $\bar{q}_{i}$. With some algebra, we find that the retailer earns profit $\Pi_{i}-\left(\Pi_{i}-\Pi_{j}\right)^{+}$, while supplier $i$ earns profit $\left(\Pi_{i}-\Pi_{j}\right)^{+}$.

- Supplier $i$ can bid a quantity-inflexible contract with $m_{i}(q, D)=\left(\Pi_{i}-\Pi_{j}\right)^{+}$if $q=\bar{q}_{i}$ and $m_{i}(q, D)=\infty$ if $q \neq \bar{q}_{i}$, for any $D$. Under this contract, the retailer orders $\bar{q}_{i}$ units and obtains a surplus of $\Pi_{i}-\left(\Pi_{i}-\Pi_{j}\right)^{+}$, while supplier $i$ obtains a surplus of $\left(\Pi_{i}-\Pi_{j}\right)^{+}$.

\section{The Incomplete Information Equilibrium}

We next consider the setting in which the suppliers have incomplete information regarding the retailer's type. We start by presenting some preliminary results which will be useful in the equilibrium analysis. We then present the equilibrium results.

\subsection{Preliminary Results}

Let $t_{i \theta}(q)=r E\left[\min \left(q, D_{\theta}\right)\right]-c_{i} q$ and $T_{i \theta}(q)=r E\left[\min \left(q, D_{\theta}\right)\right]-c_{i}(q)$. Thus, $T_{i \theta}$ includes supplier $i$ 's fixed cost (if there is one), while $t_{i \theta}$ does not. Let $\bar{q}_{i \theta}$ be the maximizer of $T_{i \theta}(q)$. Finally, let $\Pi_{i \theta}=\sup _{q \geq 0}\left\{T_{i \theta}(q)\right\}=T_{i \theta}\left(\bar{q}_{i \theta}\right)$ be the optimal expected total supply chain profit when the type- $\theta$ retailer selects supplier $i$. We can now present the first intermediate result (proofs of the lemmas can be found in the online supplement):

Lemma $1 \bar{q}_{i H}=\beta \bar{q}_{i L}, \Pi_{1 L}=t_{1 L}\left(\bar{q}_{1 L}\right), \Pi_{1 H}=\beta t_{1 L}\left(\bar{q}_{1 L}\right), \Pi_{2 L}=\left(t_{2 L}\left(\bar{q}_{2 L}\right)-F\right)^{+}, \Pi_{2 H}=$ $\left(\beta t_{2 L}\left(\bar{q}_{2 L}\right)-F\right)^{+}$, and $t_{1 L}\left(\bar{q}_{1 L}\right)<t_{2 L}\left(\bar{q}_{2 L}\right)$.

Next, it is useful to know which supplier, flexible or efficient, will provide the highest optimal expected chain profit, given the retailer's type. The answer will depend on the magnitude of 
the efficient supplier's fixed cost, $F$. Therefore, we next define four thresholds on $F$. These thresholds will be useful for characterizing the equilibrium results, as will be seen in Section 4.2. The thresholds are $F_{1}=t_{2 L}\left(\bar{q}_{2 L}\right)-t_{1 L}\left(\bar{q}_{1 L}\right), F_{2}=t_{2 H}\left(\bar{q}_{2 H}\right)-t_{1 H}\left(\bar{q}_{1 H}\right), F_{3}=F_{2}+t_{1 L}\left(\bar{q}_{1 L}\right)$ and $F_{4}=t_{2 H}\left(\bar{q}_{2 H}\right)$. Given these thresholds, we have the second useful intermediate result:

Lemma 2 The following results hold: a) $0<F_{1}<F_{2}<F_{3}<F_{4}$, b) $F_{3}>t_{2 L}\left(\bar{q}_{2 L}\right)$, and c) if the fixed cost of supplier 2, $F$, satisfies $F<F_{3}$, then $\Pi_{1 L}-\Pi_{2 L}+\Pi_{2 H}-\Pi_{1 H}>0$.

For our third intermediate result, we consider the equilibrium when the within-menu IC constraints (IC) are relaxed. In this case, supplier 1's problem can be written as follows:

$$
V_{1}=\max _{\alpha_{1 \theta}, m_{1 \theta}}\left\{\delta \alpha_{1 L} E\left[m_{1 L}\left(\hat{q}_{1 L}, D_{L}\right)\right]+(1-\delta) \alpha_{1 H} E\left[m_{1 H}\left(\hat{q}_{1 H}, D_{H}\right)\right]\right\},
$$

subject to the between-menu IR constraints:

$$
T_{1 \theta}\left(\hat{q}_{1 \theta}\right)-E\left[m_{1 \theta}\left(\hat{q}_{1 \theta}, D_{\theta}\right)\right] \geq \alpha_{1 \theta} \alpha_{2 \theta}\left(T_{2 \theta}\left(\hat{q}_{2 \theta}\right)-E\left[m_{2 \theta}\left(\hat{q}_{2 \theta}, D_{\theta}\right)\right]\right) \text {, for } \theta=\{H, L\} \text {. }
$$

Similarly, the relaxed problem for supplier 2 can be written as follows:

$$
V_{2}=\max _{\alpha_{2 \theta}, m_{2 \theta}}\left\{\delta \alpha_{2 L} E\left[m_{2 L}\left(\hat{q}_{2 L}, D_{L}\right)\right]+(1-\delta) \alpha_{2 H} E\left[m_{2 H}\left(\hat{q}_{2 H}, D_{H}\right)\right]\right\}
$$

subject to the between-menu IR constraints

$$
T_{2 \theta}\left(\hat{q}_{2 \theta}\right)-E\left[m_{2 \theta}\left(\hat{q}_{2 \theta}, D_{\theta}\right)\right] \geq \alpha_{1 \theta} \alpha_{2 \theta}\left(T_{1 \theta}\left(\hat{q}_{1 \theta}\right)-E\left[m_{1 \theta}\left(\hat{q}_{1 \theta}, D_{\theta}\right)\right]\right) \text {, for } \theta=\{H, L\}
$$

We can now see that the choice of the markup function $m_{i \theta}$ does not affect the constraints related to the markup function $m_{i \theta^{\prime}}$. Therefore, the equilibrium for the relaxed problem can be found by using Proposition 1 in a decomposed manner. In other words, there is no interaction between the $i L$ and $i H$ portions of supplier $i$ 's problem. Thus, supplier $i$ can solve two problems: (i) maximize $\delta \alpha_{i L} E\left[m_{i L}\left(\hat{q}_{i L}, D_{L}\right)\right]$ subject to constraint (5) or (6) for $\theta=L$ and (ii) maximize $(1-\delta) \alpha_{i H} E\left[m_{i H}\left(\hat{q}_{i H}, D_{H}\right)\right]$ subject to constraint (5) or (6) for $\theta=H$. Each of these problems can be solved by applying Proposition 1. We thus have the following result:

Lemma 3 The equilibrium for supplier $i$ 's contract design problem when the within-menu IC constraints are relaxed has the following characteristics: 
a) The expected profit earned by supplier $i$ is equal to $\alpha_{i L} \delta\left(\Pi_{i L}-\Pi_{j L}\right)^{+}+\alpha_{i H}(1-\delta)\left(\Pi_{i H}-\Pi_{j H}\right)^{+}$.

b) If contract-i $\theta$ is a distinctive contract, i.e., $\alpha_{i \theta}=1$ for $\theta \in\{L, H\}$, and the type- $\theta$ retailer accepts it, then the type- $\theta$ retailer orders $\hat{q}_{i \theta}=\bar{q}_{i \theta}$ units. If contract-i $\theta$ is a dummy contract, it induces the type- $\theta$ retailer to place an order for zero quantity.

In the proof of Proposition 1, we show that the equilibrium profit earned by supplier $i$ when the retailer is type- $\theta$ is $\left(\Pi_{i \theta}-\Pi_{j \theta}\right)^{+}$. Thus, the expected profit earned by supplier $i$ is as given in part a) of Lemma 3. This implies that, when $\alpha_{i \theta}=1$ and $\alpha_{j \theta}=1$, the RHS of supplier $i$ 's IR constraint, as specified in (IR1), becomes $\Pi_{i \theta}$ when $\Pi_{j \theta} \geq \Pi_{i \theta}$ and $\Pi_{j \theta}$ otherwise.

\subsection{Equilibrium Analysis}

We are now ready to analyze the equilibrium for the model with incomplete information. We first use Lemma 3 to derive a candidate equilibrium by relaxing the within-menu IC constraints. We then propose contracts that lead to the candidate equilibrium. Finally, we determine whether the omitted within-menu IC constraints are satisfied with the proposed contracts. If so, we have found the equilibrium. This approach works effectively for three cases, based on the thresholds defined in Section 4.1: i) $F \leq F_{1}$, ii) $F_{1}<F \leq F_{2}$, and iii) $F \geq F_{3}$. The analysis for the remaining case, $F_{2}<F<F_{3}$, is more complex. Before proceeding, we provide Table 1, which summarizes the relative magnitude of the optimal supply chain profits.

Table 1: Relative magnitude of supply chain profits

\begin{tabular}{|l|c|c|}
\hline \hline Scenarios & Range for $F$ & Equivalent Conditions \\
\hline (I): Efficient supplier dominates & $F \leq F_{1}$ & $\Pi_{1 L} \leq \Pi_{2 L} ; \Pi_{1 H} \leq \Pi_{2 H}$ \\
\hline (II): Both suppliers co-exist & $F_{1}<F \leq F_{2}$ & $\Pi_{1 L}>\Pi_{2 L} ; \Pi_{1 H} \leq \Pi_{2 H}$ \\
\hline (III): Flexible supplier dominates & $F>F_{2}$ & $\Pi_{1 L}>\Pi_{2 L} ; \Pi_{1 H}>\Pi_{2 H}$ \\
\hline
\end{tabular}

\subsubsection{When $F \leq F_{1}$}

When $F \leq F_{1}$, Table 1 indicates that $\Pi_{2 L} \geq \Pi_{1 L}$ and $\Pi_{2 H} \geq \Pi_{1 H}$, which follows from the definition of $F_{1}$, as well as Lemma 2. In other words, when $F<F_{1}$, the optimal expected 
supply chain profit is always higher when the retailer selects the efficient supplier, i.e., supplier 2. Therefore, for any contract that the flexible supplier can possibly offer, the efficient supplier can offer a contract that gives the retailer a higher surplus. We thus say that supplier 2 dominates supplier 1. Proposition 2 characterizes the incomplete-information equilibrium.

Proposition 2 When $F \leq F_{1}$, the equilibrium with incomplete information is unique and has the following characteristics: Supplier 2 earns expected profit equal to $\delta\left(\Pi_{2 L}-\Pi_{1 L}\right)+(1-$ $\delta)\left(\Pi_{2 H}-\Pi_{1 H}\right)$, while supplier 1 earns zero profit. This outcome can be achieved through:

- Quantity inflexible contracts in which supplier 1 bids $\left(\bar{q}_{1 \theta}, m_{1 \theta}=0\right)$, while supplier 2 bids $\left(\bar{q}_{2 \theta}, m_{2 \theta}=\Pi_{2 \theta}-\Pi_{1 \theta}\right)$.

- A two-part tariff buy-back contract in which supplier 1 bids contract-1 $\theta$ with parameters $w_{1 \theta}=c_{1}, b_{1 \theta}=0$, and $K_{1 \theta}=0$, while supplier 2 bids contract-2L with parameters $w_{2 L}=c_{2}+\rho\left(r-c_{2}\right), b_{2 L}=\rho r, \rho=\frac{\Pi_{2 L}+F-\Pi_{1 L}}{\Pi_{2 L}+F}$, and $K_{2 L}=0$, and contract-2H with parameters $w_{2 H}=c_{2}, b_{2 H}=0$, and $K_{2 H}=\Pi_{2 H}-\Pi_{1 H}+F$.

The equilibrium contracts maximize the supply chain profit, i.e., they are coordinating contracts. To outbid the flexible competitor, the efficient supplier needs to offer an expected profit of $\Pi_{1 \theta}$ to the type- $\theta$ retailer. The profit earned by the efficient supplier therefore equals $T_{2 \theta}(q)-\Pi_{1 \theta}$, i.e., the supply chain profit minus the retailer's profit. Thus, when the total supply chain profit is maximized, the efficient supplier's profit is also maximized.

When $F \leq F_{1}$, information about the retailer's type has no value for the efficient supplier, i.e., the equilibrium expected profit is the same as that for the model with full-information. Note that the dominating efficient supplier does not pay any information rent, i.e., the type- $\theta$ retailer's expected profit is just equal to her reservation profit, which is the maximum expected profit she could earn by selecting the flexible supplier, $\Pi_{1 \theta}$. This result is similar to that in Babich et al. (2012), who study a single supplier, single retailer system in which the retailer possesses private information regarding demand and the supplier offers a buy-back contract, including a lump-sum transfer payment. Those authors note that, while a simple two-part tariff contract cannot eliminate the information rent earned by the retailer, a two-part tariff with buy-back can eliminate the information rent. Specifically, the the inclusion of the buy-back 
"provides the supplier with additional leverage or an additional degree of freedom ... so that the overall channel gets arbitrarily close to the first-best optimality and at the same time allows the information rent to become arbitrarily close to zero." Proposition 2 considers two contract types that enable the dominating efficient supplier to eliminate the information rent: a two-part tariff with buy-back and a quantity inflexible contract. The former possesses the additional degree of freedom required for the elimination of rent, while the latter takes the quantity decision away from the retailer, thus providing the efficient supplier with the additional leverage required to eliminate rent. As will be seen later, when the competition between the suppliers becomes more intense (i.e., the fixed cost becomes larger), the elimination of rent may not always be possible.

Finally, the term $\left(\Pi_{i \theta}-\Pi_{j \theta}\right)^{+}$can be understood as the maximum profit that supplier $i$ can obtain when competing with supplier $j$ for the business of type- $\theta$ retailer. Part c) of Lemma 2 implies that $\Pi_{2 H}-\Pi_{1 H}>\Pi_{2 L}-\Pi_{1 L}$. Thus, supplier 2 can earn more expected profit when the retailer is type- $H$ than when the retailer is type- $L$. We thus say that the type- $H$ retailer is the "good" type for the dominating supplier 2. The contract bundle bid by supplier 2 has the following features. Contract- $2 L$ offers a high wholesale price and a low fixed charge; whereas contract- $2 H$ specifies a low wholesale price and a high fixed charge. The low-volume retailer cannot afford to pay the high fixed charge whereas the high-volume retailer is willing to pay the high fixed charge in exchange for the low wholesale price. A contract bundle with these features works well whenever the high-volume retailer is the "good" type.

\subsubsection{When $F_{1}<F \leq F_{2}$}

When $F_{1}<F \leq F_{2}$, Table 1 indicates that $\Pi_{2 L}<\Pi_{1 L}$ and $\Pi_{2 H} \geq \Pi_{1 H}$, which follows from the definitions of $F_{1}$ and $F_{2}$, as well as Lemma 2. Thus, the flexible (efficient) supplier has a cost advantage if the retailer is the low-volume (high-volume) type. In Proposition 3, we find that, under incomplete-information, the flexible supplier offers one contract (contract $1 L$ ) to attract the low-volume retailer and the efficient supplier offers one contract (contract $2 H$ ) to attract the high-volume retailer. We refer to this as the niche strategy.

Proposition 3 When $F_{1}<F \leq F_{2}$, the equilibrium with incomplete information is unique and 
has the following characteristics. Supplier 1 earns expected profit equal to $\delta\left(\Pi_{1 L}-\Pi_{2 L}\right)$, while supplier 2 earns expected profit equal to $(1-\delta)\left(\Pi_{2 H}-\Pi_{1 H}\right)$. This can be achieved through:

- Quantity inflexible contracts in which supplier 1 bids contract-1L with parameters $\left(\bar{q}_{1 L}, \Pi_{1 L}-\right.$ $\left.\Pi_{2 L}\right)$ and a dummy contract- $1 H$, while supplier 2 bids a dummy contract-2L and a quantityinflexible contract- $2 H$ with parameters $\left(\bar{q}_{2 H}, \Pi_{2 H}-\Pi_{1 H}\right)$.

- A two-part tariff buy-back contract in which supplier 1 bids contract-1L with parameters $w_{1 L}=c_{1}+\rho\left(r-c_{1}\right), b_{1 L}=\rho r, \rho=\frac{\Pi_{1 L}-\Pi_{2 L}}{\Pi_{1 L}}$, and $K_{1 L}=0$, and a dummy contract $-1 H$, while supplier 2 bids a dummy contract- $2 L$ and a two-part tariff buy-back contract- $2 H$ with parameters $w_{2 H}=c_{2}, b_{2 H}=0$, and $K_{2 H}=\Pi_{2 H}-\Pi_{1 H}$.

Proposition 3 indicates that information about the retailer's type has no value, i.e., the expected profit earned by both suppliers is the same as that in the full-information benchmark.

\subsubsection{When $F \geq F_{3}$}

When $F \geq F_{3}$, using the definition of $F_{3}$, it is easy to verify that $0=\Pi_{2 L}<\Pi_{1 L}$ and $\Pi_{2 H}<\Pi_{1 H}$. In other words, when $F \geq F_{3}$, the optimal expected supply chain profit is always higher when the retailer selects the flexible supplier, i.e., supplier 1 . Therefore, for any contract that the efficient supplier can possibly offer, the flexible supplier can offer a contract that gives the retailer a higher surplus. We thus say that supplier 1 dominates supplier 2 . In addition, part c) of Lemma 2 implies that $\Pi_{1 H}-\Pi_{2 H} \geq \Pi_{1 L}$. Thus, the expected profit available to supplier 1 , as specified in Lemma 3, is higher with the type- $H$ retailer than with the type- $L$ retailer. We therefore say that the type- $H$ retailer is the "good" type for the dominating supplier 1 . Further, when $F \geq F_{4}$, it is easy to verify that $\Pi_{2 L}=0$ and $\Pi_{2 H}=0$, i.e., the efficient supplier cannot earn positive profit from either retailer type. Thus, the dominating flexible supplier 1 acts as a monopolist. We next characterize the incomplete-information equilibrium in Proposition 4.

Proposition 4 a) When $F_{3} \leq F<F_{4}$, the equilibrium with incomplete information is unique and has the following characteristics. Supplier 1 earns an expected profit of $\delta \Pi_{1 L}+(1-\delta)\left(\Pi_{1 H^{-}}\right.$ $\left.\Pi_{2 H}\right)$, while supplier 2 earns zero profit. This outcome can be achieved through:

- A two-part tariff buy-back contract in which supplier 1 bids contract-1L with parameters $w_{1 L}=\rho\left(r-c_{1}\right)+c_{1}, b_{1 L}=\rho r, K_{1 L}=(1-\rho) \Pi_{1 L}$, and $\rho=1-\frac{\Pi_{2 H}}{\Pi_{1 H}-\Pi_{1 L}}$, and contract- $1 H$ 
with parameters $w_{1 H}=c_{1}, b_{1 H}=0$, and $K_{1 H}=\Pi_{1 h}-\Pi_{2 h}$, while supplier 2 offers a dummy contract- $2 L$ and contract- $2 H$ with parameters $w_{2 H}=c_{2}, b_{2 H}=0$, and $K_{2 H}=F$.

b) When $F \geq F_{4}$, supplier 1 acts as a monopolist and earns expected profit equal to $\delta \Pi_{1 L}+(1-$ $\delta) \Pi_{1 H}$, while supplier 2 does not bid any distinctive contract. This outcome can be achieved through a one-size-fits-all two-part tariff buy-back contract with $w=b=r$, and $K=0$.

When $F \geq F_{3}$, the contracts offered by the dominating flexible supplier are coordinating contracts, i.e., $\hat{q}_{1 \theta}=\bar{q}_{1 \theta}$, and information regarding the retailer's type has no value.

The results for the case in which $F>F_{4}$ are identical to those in Babich et al. (2012), who find that, if the supplier offers optimal contracts in which the buy-back price is arbitrarily close to the retail price, the retailer (of either type) will order (nearly) the system optimal quantity. In addition, the information rent paid by the supplier to the retailer will be (almost) zero, implying that the supplier can extract (almost) all of the optimal supply chain profit. In our model, when $F>F_{4}$, the fixed cost is so large that the efficient supplier cannot profitably serve either retailer type. Thus, the efficient supplier will not offer any contracts and our model reduces to the Babich et al. (2012) model, in which the flexible supplier serves the retailer. Our coordinating contract in this case has $w=b=r$, enabling the supplier to coordinate the supply chain and extract all of the information rent from the retailer.

Before analyzing the case in which $F_{2}<F<F_{3}$, which is significantly more complex, in Table 2 we summarize the results for the four cases we have analyzed so far.

\subsubsection{When $F_{2}<F<F_{3}$}

When $F_{2}<F<F_{3}$, Table 1 indicates that $\Pi_{2 L}<\Pi_{1 L}$ and $\Pi_{2 H}<\Pi_{1 H}$, which follows from the definitions of $F_{2}$ and $F_{3}$. Therefore, as in the case when $F \geq F_{3}$, supplier 1 dominates supplier 2. In addition, part c) of Lemma 2 implies $\Pi_{1 L}-\Pi_{2 L}>\Pi_{1 H}-\Pi_{2 H}$. Thus, in contrast to the case when $F \geq F_{3}$, the type- $L$ retailer is the "good" type agent for supplier 1 . In other words, the expected profit available to supplier 1 is higher with the type- $L$ retailer than with the type- $H$ retailer. The fact that the low-volume retailer may be the "good" type stands in contrast to the existing literature, which takes the reservation profit as fixed and exogenously 
Table 2: Partial summary of equilibrium results under incomplete information

\begin{tabular}{|c|c|c|c|c|}
\hline & $F \leq F_{1}$ & $F_{1}<F \leq F_{2}$ & $F_{3} \leq F<F_{4}$ & $F \geq F_{4}$ \\
\hline Dominating & Supplier 2 & Neither & Supplier 1 & Supplier 1 \\
\hline Contract $1 L$ & $\begin{array}{l}w_{1 L}=c_{1} \\
b_{1 L}=0 \\
K_{1 L}=0\end{array}$ & $\begin{array}{l}w_{1 L}=c_{1}+\rho\left(r-c_{1}\right) \\
b_{1 L}=\rho r \\
K_{1 L}=0 \\
\rho=\frac{\Pi_{1 L}-\Pi_{2 L}}{\Pi_{1 L}}\end{array}$ & $\begin{array}{l}w_{1 L}=\rho\left(r-c_{1}\right)+c_{1} \\
b_{1 L}=\rho r \\
K_{1 L}=(1-\rho) \Pi_{1 L} \\
\rho=1-\frac{\Pi_{2 H}}{\Pi_{1 H}-\Pi_{1 L}}\end{array}$ & $\begin{array}{l}w_{1 L}=r \\
b_{1 L}=r \\
K_{1 L}=0\end{array}$ \\
\hline Contract $1 H$ & $\begin{array}{l}w_{1 H}=c_{1} \\
b_{1 H}=0 \\
K_{1 H}=0\end{array}$ & dummy & $\begin{array}{l}w_{1 H}=c_{1} \\
b_{1 H}=0 \\
K_{1 H}=\Pi_{1 H}-\Pi_{2 H}\end{array}$ & $\begin{array}{l}w_{1 H}=r \\
b_{1 H}=r \\
K_{1 H}=0\end{array}$ \\
\hline Contract $2 L$ & $\begin{array}{l}w_{2 L}=c_{2}+\rho\left(r-c_{2}\right) \\
b_{2 L}=\rho r \\
K_{2 L}=0 \\
\rho=\frac{\Pi_{2 L}+F-\Pi_{1 L}}{\Pi_{2 L}+F}\end{array}$ & dummy & dummy & dummy \\
\hline Contract $2 H$ & $\begin{array}{l}w_{2 H}=c_{2} \\
b_{2 H}=0 \\
K_{2 H}=\Pi_{2 H}-\Pi_{1 H}+F\end{array}$ & $\begin{array}{l}w_{2 H}=c_{2} \\
b_{2 H}=0 \\
K_{2 H}=\Pi_{2 H}-\Pi_{1 H}+F\end{array}$ & $\begin{array}{l}w_{2 H}=c_{2} \\
b_{2 H}=0 \\
K_{2 H}=F\end{array}$ & dummy \\
\hline
\end{tabular}

specified. To understand why this difference arises, let $\Pi_{R}$ denote a fixed and exogenously specified reservation profit. Since the optimal supply chain profit is increasing in the demand volume, i.e., $\Pi_{i H}>\Pi_{i L}$, given a type- $i$ retailer, it is always true that $\Pi_{i H}-\Pi_{R}>\Pi_{i L}-\Pi_{R}$, i.e., the high-type retailer is always the "good" type when the reservation profit is fixed. In contrast, when the reservation value is not fixed, but rather is endogenously-determined, either retailer type can be the "good" type, depending on the value of the fixed cost, $F$.

The fact that the low-volume retailer may be the "good" type complicates the analysis. In particular, we cannot identify a set of $m_{1 \theta}(q, D)$ functions that can achieve the outcome of the relaxed problem, i.e., Lemma 3 cannot be directly applied. This is because the within-menu IC constraint for $\theta=L$ is often violated, as demonstrated in the online supplement. Thus, to advance our analysis further, we impose two assumptions. First, we assume that the random demand $D_{L}$ is uniformly distributed between 0 and 1 . Because $D_{H}$ is equal in distribution to $\beta D_{L}$, we find that $D_{H}$ is uniformly distributed between 0 and $\beta$. Under this assumption, we 
have the following useful expressions, whose derivation can be found in the online supplement:

- $\bar{q}_{1 L}=\frac{r-c_{1}}{r}, \bar{q}_{1 H}=\frac{\beta\left(r-c_{1}\right)}{r}, \bar{q}_{2 L}=\frac{r-c_{2}}{r}, \bar{q}_{2 H}=\frac{\beta\left(r-c_{2}\right)}{r}$

- $\Pi_{1 L}=\frac{\left(r-c_{1}\right)^{2}}{2 r}, \Pi_{1 H}=\frac{\beta\left(r-c_{1}\right)^{2}}{2 r}, \Pi_{2 L}=\left(\frac{\left(r-c_{2}\right)^{2}}{2 r}-F\right)^{+}, \Pi_{2 H}=\frac{\beta\left(r-c_{2}\right)^{2}}{2 r}-F$

- $F_{2}=\frac{\beta\left(2 r-c_{1}-c_{2}\right)\left(c_{1}-c_{2}\right)}{2 r}$.

Second, we focus on two-part tariff buy-back contracts because they are able to achieve the equilibrium outcomes in the previous cases and because they have been widely used in the previous literature. Specifically, for the remainder of this section, we assume that contract-i $\theta$ specifies that the wholesale price, $w_{i \theta}$, the buy-back rate, $b_{i \theta}$, and the fixed charge, $K_{i \theta}$.

We now proceed with the analysis. There are three cases to consider:

- $\alpha_{1 L}=1$ and $\alpha_{1 H}=0$ : Supplier 1 offers contract- $1 L$ to attract the low-volume retailer and exclude the high-volume retailer. Let $\pi_{1}^{1}=\delta\left(\Pi_{1 L}-\Pi_{2 L}\right)$ denote supplier 1's expected profit in this case, which is a function of $F$ because $\Pi_{2 L}$ depends on $F$. Supplier 2 offers contract- $2 H$ to attract the type- $H$ retailer. However, the markup of contract- $2 H$ must be low enough to ensure that supplier 1 is not interested in changing his contract bundle.

- $\alpha_{1 L}=1$ and $\alpha_{1 H}=1$ : Supplier 1 offers contract- $1 L$ and contract- $1 H$ to attract the type$L$ and type- $H$ retailer, respectively. Let $\pi_{1}^{2}$ denote supplier 1's expected profit in this case, which is a complex function of $F$. We will derive supplier 1's optimal two-contract solution later (see Lemma 4). Supplier 2 offers a zero-markup contract menu designed to ensure that the retailer orders the chain-optimal quantity.

- $\alpha_{1 L}=0$ and $\alpha_{1 H}=1$ : Supplier 1 offers contract- $1 H$ to attract the high-volume retailer and exclude the low-volume retailer. The best outcome that supplier 1 can achieve is to obtain an expected profit of $(1-\delta)\left(\Pi_{1 H}-\Pi_{2 H}\right)$. However, supplier 1 could alternatively offer a contract to attract both retailer types with $w_{1}=c_{1}, b_{1}=0$, and $K_{1}=\Pi_{1 H}-\Pi_{2 H}$. The dominated supplier 2 cannot match this contract. Under this alternative contract, supplier 1 is able to earn an expected profit of $\Pi_{1 H}-\Pi_{2 H}>(1-\delta)\left(\Pi_{1 H}-\Pi_{2 H}\right)$. Hence, setting $\alpha_{1 L}=0$ and $\alpha_{1 H}=1$ is not optimal for supplier 1 and we can ignore this possibility.

Thus, we need to compare $\pi_{1}^{1}$ and $\pi_{1}^{2}$ to find the globally optimal solution for supplier 1 . Once supplier 1's strategy is determined, we can identify the equilibrium strategy of supplier 2 .

We next present the formulation for the case with $\alpha_{1 L}=1$ and $\alpha_{1 H}=1$. The online supplement provides the detailed derivations. The best response of the type- $L$ retailer to 
contract-1 $\theta$, with parameters $w_{1 \theta}, b_{1 \theta}$, and $K_{1 \theta}$, is to order $\frac{r-w_{1 \theta}}{r-b_{1 \theta}}$ units, while the best response of the type- $H$ retailer to contract- $1 \theta$ is to order $\frac{\beta\left(r-w_{1 \theta}\right)}{r-b_{1 \theta}}$ units. The expected profit of the type- $L$ retailer who accepts contract- $1 L$ is $\frac{1}{2} \frac{\left(r-w_{1 L}\right)^{2}}{\left(r-b_{1 L}\right)}-K_{1 L}$, while the expected profit of the type- $H$ retailer who accepts contract- $1 H$ is $\frac{\beta}{2} \frac{\left(r-w_{1 H}\right)^{2}}{\left(r-b_{1 H}\right)}-K_{1 H}$. When $\alpha_{1 L}=1$ and $\alpha_{1 H}=1$, supplier 1 thus faces the following optimization problem:

$$
\begin{aligned}
\pi_{1}^{2}= & \max _{w_{1 \theta}, b_{1 \theta}, K_{1 \theta}} \delta\left[\left(w_{1 L}-c_{1}\right)\left(\frac{r-w_{1 L}}{r-b_{1 L}}\right)-\frac{b_{1 L}}{2}\left(\frac{r-w_{1 L}}{r-b_{1 L}}\right)^{2}+K_{1 L}\right] \\
& +(1-\delta)\left[\beta\left(w_{1 H}-c_{1}\right)\left(\frac{r-w_{1 H}}{r-b_{1 H}}\right)-\frac{\beta b_{1 H}}{2}\left(\frac{r-w_{1 H}}{r-b_{1 H}}\right)^{2}+K_{1 H}\right],
\end{aligned}
$$

subject to the within-menu IC constraints

$$
\begin{aligned}
I C_{1 L} & : \frac{1}{2} \frac{\left(r-w_{1 L}\right)^{2}}{\left(r-b_{1 L}\right)}-K_{1 L} \geq \frac{1}{2} \frac{\left(r-w_{1 H}\right)^{2}}{\left(r-b_{1 H}\right)}-K_{1 H}, \\
I C_{1 H} & : \quad \frac{\beta}{2} \frac{\left(r-w_{1 H}\right)^{2}}{\left(r-b_{1 H}\right)}-K_{1 H} \geq \frac{\beta}{2} \frac{\left(r-w_{1 L}\right)^{2}}{\left(r-b_{1 L}\right)}-K_{1 L},
\end{aligned}
$$

and the between-menu IR constraints

$$
\begin{array}{ll}
I R_{1 L} & : \frac{1}{2} \frac{\left(r-w_{1 L}\right)^{2}}{\left(r-b_{1 L}\right)}-K_{1 L} \geq \Pi_{2 L}, \\
I R_{1 H} & : \quad \frac{\beta}{2} \frac{\left(r-w_{1 H}\right)^{2}}{\left(r-b_{1 H}\right)}-K_{1 H} \geq \Pi_{2 H} .
\end{array}
$$

The dominated supplier 2 offers contracts that maximize the supply chain profit and have zero markup. This implies that the RHS of supplier 1's IR constraints are $\Pi_{2 \theta}$ for $\theta \in\{L, H\}$.

Finally, to describe the best two-contract solutions, we define the following notation:

$$
g_{1}=\frac{r \delta(\beta-1)-c_{1} \beta(1-\delta)}{\delta(\beta-1)-\beta(1-\delta)} \quad \text { and } \quad g_{2}=r-\sqrt{\frac{\beta\left(r-c_{2}\right)^{2}-2 r F}{\beta-1}}
$$

Lemma 4 When $F_{2}<F<F_{3}$, the optimal solution to (7) depends on four different patterns of system parameters.

1. Suppose that $\frac{r-c_{2}}{c_{1}-c_{2}} \geq \frac{(1-\delta) \beta}{\delta(\beta-1)}$.

1a. If $F_{2}<F<\frac{\left(r-c_{2}\right)^{2}}{2 r}$, then the optimal contract-1L has parameters $w_{1 L}=c_{1}, b_{1 L}=0$, 
and $K_{1 L}=\Pi_{1 L}-\Pi_{2 L}$. The optimal contract- $1 H$ has parameters $w_{1 H}=c_{2}, b_{1 H}=0$, and $K_{1 H}=F$.

1b. If $\frac{\left(r-c_{2}\right)^{2}}{2 r} \leq F<F_{3}$, then the optimal contract-1L has parameters $w_{1 L}=c_{1}, b_{1 L}=0$, and $K_{1 L}=\Pi_{1 L}-\Pi_{2 L}$. The optimal contract- $1 H$ has parameters $w_{1 H}=g_{2}, b_{1 H}=0$, and $K_{1 H}=\frac{\beta\left(r-g_{2}\right)^{2}}{2 r}-\Pi_{2 H}$.

2. Suppose that $\frac{r-c_{2}}{c_{1}-c_{2}}<\frac{(1-\delta) \beta}{\delta(\beta-1)}$. Then $c_{1}>g_{1}>c_{2}$. Let $F_{3}^{\prime}=\frac{\beta\left(r-c_{2}\right)^{2}-(\beta-1)\left(r-g_{1}\right)^{2}}{2 r}$. When $F=F_{3}^{\prime}, g_{1}=g_{2}$. It holds that $\frac{\left(r-c_{2}\right)^{2}}{2 r}<F_{3}^{\prime}<F_{3}$.

2a. If $F_{2}<F<F_{3}^{\prime}$, the optimal contract-1L has parameters $w_{1 L}=c_{1}, b_{1 L}=0$, and $K_{1 L}=\Pi_{1 L}+\frac{(\beta-1)\left(r-g_{1}\right)^{2}}{2 r}-\Pi_{2 H}$. The optimal contract-1H has parameters $w_{1 H}=g_{1}$, $b_{1 H}=0$, and $K_{1 H}=\frac{\beta\left(r-g_{1}\right)^{2}}{2 r}-\Pi_{2 H}$.

2b. If $F_{3}^{\prime} \leq F<F_{3}$, the optimal contract-1L has parameters $w_{1 L}=c_{1}, b_{1 L}=0$, and $K_{1 L}=\Pi_{1 L}-\Pi_{2 L}$. The optimal contract- $1 H$ has parameters $w_{1 H}=g_{2}, b_{1 H}=0$, and $K_{1 H}=\frac{\beta\left(r-g_{2}\right)^{2}}{2 r}-\Pi_{2 H}$.

If $F_{3}^{\prime}<F_{2}$, then case $2 b$ applies whenever $\frac{r-c_{2}}{c_{1}-c_{2}}<\frac{(1-\delta) \beta}{\delta(\beta-1)}$.

We refer to the contract menus described in Lemma 4 as a hybrid combination of contracts. The contract assigned to the low-volume retailer, which is the "good" type agent of supplier 1, is always a coordinating contract. However, the contract assigned to the high-volume retailer is a wholesale price contract with a wholesale price that is lower than supplier 1's marginal cost.

We are now ready to compare the one-contract and two-contract solutions. After doing so, we obtain the overall equilibrium solution when $F_{2}<F<F_{3}$, as specified below:

Proposition 5 There exists a threshold $F_{2}^{\prime}$, where $F_{2}<F_{2}^{\prime}<F_{3}$, such that the one-contract solution, attracting the low-volume retailer and excluding the high-volume retailer, is optimal for the dominating supplier 1 if and only if $F_{2}<F<F_{2}^{\prime}$. For $F_{2}^{\prime} \leq F<F_{3}$, the two contract solution specified in Lemma 4 is optimal for supplier 1. The equilibrium contract forms for each case are shown in Table 3.

The detailed expression for $F_{2}^{\prime}$ is quite complex. Thus, we provide the exact characterization of $F_{2}^{\prime}$ in the proof of Proposition 5. Interestingly, the theorem implies that the efficient supplier, who has a cost disadvantage when his fixed cost is higher than $F_{2}$, has a chance to win the 
Table 3: Summary of equilibrium results under incomplete information for $F_{2}<F<F_{3}$

\begin{tabular}{|l|l|l|}
\hline \hline & $F_{2}<F<F_{2}^{\prime}$ & $F_{2}^{\prime} \leq F<F_{3}$ \\
\hline \hline \multirow{3}{*}{ Contract-1 $L$} & $w_{1 L}=c_{1}+\rho\left(r-c_{1}\right)$, & \\
& $b_{1 L}=\rho r, K_{1 L}=0$, & As specified in Lemma 4 \\
& $\rho=\frac{\Pi_{1 L}-\Pi_{2 L}}{\Pi_{1 L}}$ & \\
\hline Contract-1 $H$ & Dummy & As specified in Lemma 4 \\
\hline \hline Contract-2L & Dummy & $w_{2 L}=c_{2}, b_{2 L}=0, K_{2 L}=F$ \\
\hline \multirow{3}{*}{ Contract-2 $H$} & $w_{2 H}=c_{2}$, & \\
& $b_{2 H}=0$, & $w_{2 H}=c_{2}, b_{2 H}=0, K_{2 H}=F$ \\
& $K_{2 H}=\pi_{1}^{1}-\pi_{1}^{2}+F$ & \\
\hline \hline
\end{tabular}

business of the high-volume retailer by offering a coordinating contract. This occurs when the efficient supplier's fixed cost is sufficiently close to $F_{2}$, i.e., when $F_{2}<F<F_{2}^{\prime}$.

We next provide some intuition for these results. To reduce the information rent paid to the "good" type retailer, the dominating flexible supplier has two options: exclusion, i.e., not offering a contract to one of the retailer types, and distortion, i.e., not designing the contract to induce the system optimal order quantity. Here, information rent refers to the additional profit, beyond her reservation profit (the profit she would earn if she chose the best contract offered by the other supplier), allocated to the retailer in order to get the retailer to choose the contract designed for her type rather than the contract designed for the other type.

- When $F$ is only slightly higher than $F_{2}$, i.e., $F_{2}<F<F_{2}^{\prime}$, and thus the flexible supplier's dominance of the efficient supplier is weak, the rent paid to the low-volume ("good") retailer is too high to justify offering a two-contract bundle. Thus, the flexible supplier uses the exclusion strategy, i.e., the flexible supplier gives up serving the high-volume retailer in exchange for an elimination of rent paid to the low-volume retailer.

- When $F_{2}^{\prime} \leq F<F_{3}^{\prime}$, i.e., the flexible supplier's advantage over the efficient supplier is more substantial, the flexible supplier can use the distortion strategy to reduce rent paid to the low-volume retailer. In this case, the flexible supplier is able to serve both retailer types, but must pay some rent to the low-volume retailer.

- When $F_{3}^{\prime} \leq F<F_{3}$, the flexible supplier can use the distortion strategy to serve both retailer types and simultaneously eliminate the rent paid to the low-volume retailer because the large value of $F$ provides the flexible supplier with the ability to extract more surplus from the retailer. 
High Volume Retailer

Asymmetric Information Solution
\begin{tabular}{|c|c|c|c|}
\hline Supplier 2 wins, & Supplier 2 wins, & Supplier 1 wins, & Supplier 1 wins, \\
Retailer earns & Retailer earns \\
$\Pi_{1 \mathrm{H}}$ & $<\Pi_{2 \mathrm{H}}$ & $\Pi_{2 \mathrm{H}}$ & $\Pi_{2 \mathrm{H}}$ \\
\hline
\end{tabular}

Full Information Solution

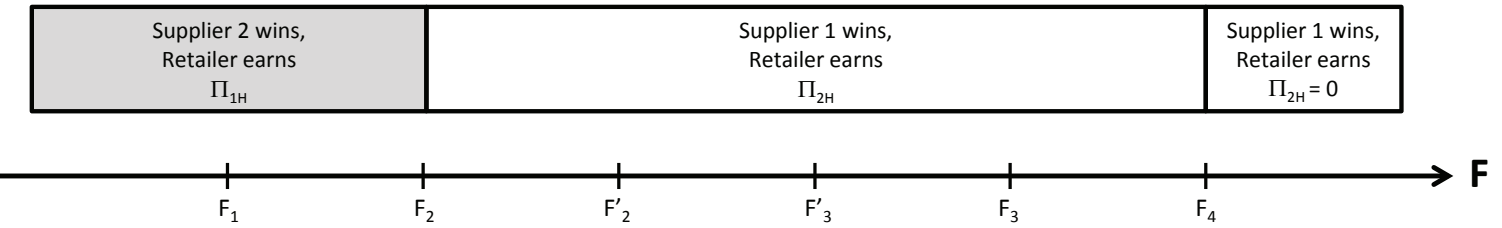

Asymmetric Information Solution

\begin{tabular}{|c|c|c|c|c|}
\hline Supplier 2 wins, & Supplier 1 wins, & Supplier 1 wins, & Supplier 1 wins, & Supplier 1 wins, \\
Retailer earns & Retailer earns & Retailer earns & Retailer earns & $\Pi_{2 \mathrm{~L}}=0$ \\
$\Pi_{1 \mathrm{~L}}$ & $\Pi_{2 \mathrm{~L}}$ & $>\Pi_{2 \mathrm{~L}}$ & $\Pi_{2 \mathrm{~L}}$ & $\Pi_{\mathrm{L}}$ \\
\hline
\end{tabular}

Full Information Solution

\begin{tabular}{|c|c|c|}
\hline Supplier 2 wins, & Supplier 1 wins, & Supplier 1 wins, \\
Retailer earns & Retailer earns & Retailer earns \\
$\Pi_{1 \mathrm{~L}}$ & $\Pi_{2 \mathrm{~L}}$ & $\Pi_{2 \mathrm{~L}}=0$ \\
\hline
\end{tabular}

\section{Low Volume Retailer}

Figure 2: Comparison of equilibrium results: asymmetric information vs. full information

\section{Managerial Insights and Contributions}

This paper contributes to the literature and to managerial practice by studying contracting under asymmetric information with two heterogeneous competing suppliers. To highlight the insights provided by this work, it is useful to compare our results to two alternative settings: (1) two suppliers with perfect information, and (2) one supplier with asymmetric information.

By comparing our results with (1), as shown in Figure 2, we can demonstrate the impact of information asymmetry on supplier competition. Asymmetric information has no impact on which supplier serves the low-volume retailer, but can (when $F_{2}<F \leq F_{2}^{\prime}$ ) change which supplier serves the high-volume retailer. In this case, the flexible supplier's dominance over the efficient supplier is slight and thus the flexible supplier gives up serving the high-volume retailer in order to avoid paying the information rent that would be required to get the low-volume retailer to reveal her type. This exclusion strategy results in lower profits for the high-volume retailer, relative to what she would earn under perfect information, because the efficient supplier 
no longer faces competition from the flexible supplier for the high-volume retailer. In only one other case (when $F_{2}^{\prime} \leq F<F_{3}^{\prime}$ ) does the profit earned by the retailer differ from what she would earn under perfect information. In this case, the low-volume retailer earns a higher profit under asymmetric information than under perfect information because the flexible supplier serves both retailer types and pays information rent to the low-volume retailer to prevent the low-volume retailer from choosing the contract designed for the high-volume retailer.

By comparing our results with (2), we can demonstrate the impact of competition on contracting under information asymmetry. A setting with a single flexible supplier with asymmetric information regarding the retailer's volume is considered in Babich et al. (2012). The results for a setting with a single efficient supplier are similar. In both cases, the single supplier can design contracts so that the retailer orders the system optimal quantity and the supplier extracts all of the available profit. In contrast, competition between the suppliers enables the retailer to extract some of the supply chain profit. As shown in Figure 2, the high-volume (lowvolume) retailer earns positive profit when $F<F_{4}\left(F<F_{3}\right)$. In addition, in some cases (when $F_{2}^{\prime} \leq F<F_{3}$ ), the equilibrium contracts under competition will not induce the high-volume retailer to order the system optimal quantity.

Finally, there are a number of ways to extend this research. One key question is whether other contract forms can be effective for suppliers under asymmetric information regarding the retailer's volume. For example, the suppliers may be able to learn about the retailer's volume by observing her order quantity. If so, the suppliers could take advantage of this learning through proper contract design, e.g., by making the contract terms contingent on the amount ordered.

\section{Acknowledgements}

Author names are listed alphabetically and all authors contributed equally.

\section{References}

Akan, M., Ata, B., and Lariviere, M. A. (2011). Asymmetric information and economies of scale in service contracting. Manufacturing and Service Operations Management, 13(1), 58-72.

Babich, V., Li, H., Ritchken, P., and Wang, Y. (2012). Contracting with asymmetric demand information in supply chains. European Journal of Operational Research, 217(2), 333 - 341. 
Burnetas, A., Gilbert, S. M., and Smith, C. E. (2007). Quantity discounts in single-period supply contracts with asymmetric demand information. IIE Transactions, 39(5), 465-479.

Cachon, G. P. and Kök, G. (2010). Competing manufacturers in a retail supply chain: on contractual form and coordination. Management Science, 56(3), 571-589.

Cachon, G. P. and Lariviere, M. A. (2001). Contracting to assure supply: How to share demand forecasts in a supply chain. Management Science, 47(5), 629-646.

Chen, L. G., Ding, D., and Ou, J. (2014). Power structure and profitability in assembly supply chains. Production and Operations Management, Forthcoming.

Chen-Ritzo, C. H., Harrison, T. P., Kwasnica, A. M., and Thomas, D. J. (2005). Better, faster, cheaper: An experimental analysis of a multiattribute reverse auction mechanism with restricted information feedback. Management Sciences, 51(12), 1753-1762.

Corbett, C. J. and Groote, X. d. (2000). A supplier's optimal quantity discount policy under asymmetric information. Management Science, 46(3), 444-450.

Corbett, C. J., Zhou, D., and Tang, C. S. (2004). Designing supply contracts: Contract type and information asymmetry. Management Science, 50(4), 550-559.

Dai, T., Li, Z., and Sun, D. (2012). Equity-based incentives and supply chain buy-back contracts. Decision Sciences, 43(4), 661-686.

Fox, E. J., Metters, R., and Semple, J. (2006). Optimal inventory policy with two suppliers. Operations Research, 54(2), 389-393.

Gan, X., Sethi, S. P., and Zhou, J. (2010). Commitment-penalty contracts in drop-shipping supply chains with asymmetric demand information. European Journal of Operational Research, 204(3), $449-462$.

Ha, A. Y. (2001). Supplier-buyer contracting: Asymmetric cost information and cutoff level policy for buyer participation. Naval Research Logistics, 48(1), 41-64.

Kouvelis, P., Chambers, C., and Wang, H. (2006). Supply chain management research and production and operations management: Review, trends, and opportunities. Production and Operations Management, 15(3), 449-469.

Lee, C.-Y. and Yang, R. (2013). Supply chain contracting with competing suppliers under asymmetric information. IIE Transactions, 45(1), 25-52.

Mukhopadhyay, S. K., Su, X., and Ghose, S. (2009). Motivating retail marketing effort: Optimal contract design. Production and Operations Management, 18(2), 197-211.

Ozer, O. and Raz, G. (2011). Supply chain sourcing under asymmetric information. Production and Operations Management, 20(1), 92-115.

Ozer, O. and Wei, W. (2006). Strategic commitments for an optimal capacity decision under asymmetric forecast information. Management Science, 52(8), 1238-1257.

Shi, R., Zhang, J., and Ru, J. (2013). Impacts of power structure on supply chains with uncertain demand. Production and Operations Management, 22(5), 1232-1249. 


\section{A. Proofs of Propositions}

\section{Proof of Proposition 1}

Part a): We show that $\hat{q}_{i}=\bar{q}_{i}$ by contradiction. Suppose that contract- $i$ is determined by a markup function $m_{i}(q, D)$ and that, under contract- $i$, it is optimal for the retailer to order $\hat{q}_{i}$ units, where $\hat{q}_{i} \neq \bar{q}_{i}$. In other words, $\hat{q}_{i}$ maximizes $T_{i}(q)-E\left[m_{i}(q, D)\right]$. Under this contract, the supplier earns $E\left[m_{i}\left(\hat{q}_{i}, D\right)\right]$, while the retailer earns $T_{i}\left(\hat{q}_{i}\right)-E\left[m_{i}\left(\hat{q}_{i}, D\right)\right]$.

Note that $T_{i}\left(\hat{q}_{i}\right)<T_{i}\left(\bar{q}_{i}\right)=\Pi_{i}$. Let $\delta=\Pi_{i}-T_{i}\left(\hat{q}_{i}\right)>0$. We now construct an alternative contract to improve supplier $i$ 's profit without making the retailer worse off. That contract specifies $m_{i}^{a}(q, D)=E\left[m_{i}\left(\hat{q}_{i}, D\right)\right]+\frac{\delta}{2}$ if $q=\bar{q}_{i}$ and $m_{i}^{a}(q, D)=\infty$ if $q \neq \bar{q}_{i}$. Under this contract, the supplier earns $\frac{\delta}{2}$ more than under the original contract. Also, the retailer will order $\bar{q}_{i}$ under this contract, leading to a total supply chain profit equal to $\Pi_{i}$. Thus, the retailer's expected profit under this contract is

$$
\begin{aligned}
\Pi_{i}-E\left[m_{i}^{a}\left(\bar{q}_{i}, D\right)\right] & =\Pi_{i}-\left(E\left[m_{i}\left(\hat{q}_{i}, D\right)\right]+\frac{\delta}{2}\right)=\Pi_{i}-E\left[m_{i}\left(\hat{q}_{i}, D\right)\right]-\frac{1}{2}\left(\Pi_{i}-T_{i}\left(\hat{q}_{i}\right)\right) \\
& =\frac{\Pi_{i}}{2}+\frac{T_{i}\left(\hat{q}_{i}\right)}{2}-E\left[m_{i}\left(\hat{q}_{i}, D\right)\right]>T_{i}\left(\hat{q}_{i}\right)-E\left[m_{i}\left(\hat{q}_{i}, D\right)\right]
\end{aligned}
$$

where the last line follows from $\Pi_{i}>T_{i}\left(\hat{q}_{i}\right)$. Therefore, we have created an alternative contract that offers more expected profit to both the retailer and the supplier. This contradicts the optimality of the original contract, $m_{i}(q, D)$.

Part b): We next show that the equilibrium profit earned by supplier $i$ is $\left(\Pi_{i}-\Pi_{j}\right)^{+}$. Because $\hat{q}_{i}=\bar{q}_{i}$ and $\Pi_{i}=T_{i}\left(\bar{q}_{i}\right)$, the between-menu IR constraint is: $\Pi_{i}-E\left[m_{i}\left(\bar{q}_{i}, D\right)\right] \geq \Pi_{j}-$ $E\left[m_{j}\left(\bar{q}_{j}, D\right)\right]$. The best response of supplier $i$ must satisfy $E\left[m_{i}\left(\bar{q}_{i}, D\right)\right] \leq\left(\Pi_{i}-\Pi_{j}+E\left[m_{j}\left(\bar{q}_{j}, D\right]\right)^{+}\right.$. By symmetry, the best response of supplier $j$ must satisfy $E\left[m_{j}\left(\bar{q}_{j}, D\right)\right] \leq\left(\Pi_{j}-\Pi_{i}+E\left[m_{i}\left(\bar{q}_{i}, D\right)\right]\right)^{+}$. These best response functions yield $E\left[m_{i}\left(\bar{q}_{i}, D\right)\right]=\left(\Pi_{i}-\Pi_{j}\right)^{+}$and $E\left[m_{j}\left(\bar{q}_{j}, D\right)\right]=\left(\Pi_{j}-\Pi_{i}\right)^{+}$.

We next show that neither supplier has an incentive to deviate from this solution. Consider what happens if supplier $i$ sets $E\left[m_{i}\left(\bar{q}_{i}, D\right)\right]=\Pi_{i}-\Pi_{j}+\epsilon$. At this solution the retailer earns profit $\Pi_{i}-E\left[m_{i}\left(\bar{q}_{i}, D\right)\right]=\Pi_{i}-\left(\Pi_{i}-\Pi_{j}+\epsilon\right)=\Pi_{j}-\epsilon$ if supplier $i$ is chosen and profit $\Pi_{j}-E\left[m_{j}\left(\bar{q}_{j}, D\right)\right]=\Pi_{j}$ if supplier $j$ is chosen. If $\epsilon>0$, supplier $i$ will lose by deviating. If $\epsilon<0$, 
supplier $i$ will earn less profit by deviating. Thus, supplier $i$ will not deviate. Next consider what happens if supplier $j$ sets $E\left[m_{j}\left(\bar{q}_{j}, D\right)\right]=\epsilon$. At this solution the retailer earns profit $\Pi_{i}-E\left[m_{i}\left(\bar{q}_{i}, D\right)\right]=\Pi_{i}-\left(\Pi_{i}-\Pi_{j}\right)=\Pi_{j}$ if supplier $i$ is chosen and profit $\Pi_{j}-E\left[m_{j}\left(\bar{q}_{j}, D\right)\right]=$ $\Pi_{j}-\epsilon$ if supplier $j$ is chosen. If $\epsilon<0$, supplier $j$ will earn negative profit by deviating. If $\epsilon>0$, supplier $j$ lose by deviating. Thus, supplier $j$ will not deviate.

Finally, we show that this equilibrium is unique. Assume that another point, $E\left[m_{i}\left(\bar{q}_{i}, D\right)\right]=$ $\Pi_{i}-\Pi_{j}+\epsilon_{i}$ and $E\left[m_{j}\left(\bar{q}_{j}, D\right)\right]=\epsilon_{j}$, is also an equilibrium. At this solution the retailer earns profit $\Pi_{i}-E\left[m_{i}\left(\bar{q}_{i}, D\right)\right]=\Pi_{i}-\left(\Pi_{i}-\Pi_{j}+\epsilon_{i}\right)=\Pi_{j}-\epsilon_{i}$ if supplier $i$ is chosen and profit $\Pi_{j}-E\left[m_{j}\left(\bar{q}_{j}, D\right)\right]=\Pi_{j}-\epsilon_{j}$ if supplier $j$ is chosen. If $\epsilon_{i}<\epsilon_{j}$, supplier $i$ wins and supplier $j$ can deviate by reducing $\epsilon_{j}$ to be less than $\epsilon_{i}$ and win. If $\epsilon_{i}>\epsilon_{j}$ supplier $j$ wins and supplier $i$ can deviate by reducing $\epsilon_{i}$ to less than $\epsilon_{j}$ and win. If $\epsilon_{i}=\epsilon_{j}$, either supplier can break the tie and win by reducing their respective $\epsilon$.

\section{Proof of Proposition 2}

Our approach is to solve for the equilibrium by ignoring the within-menu IC constraint (IC) and then to verify that this solution is feasible given the omitted constraints. Recall that $\Pi_{2 \theta}-\Pi_{1 \theta}>0$ for $\theta \in\{L, H\}$, when $F<F_{1}$. From Lemma 3, the equilibrium of the relaxed problem has the following characteristics: (i) regardless of the retailer's type and the selected supplier, the retailer will order the system optimal quantity, $\bar{q}_{i \theta}$; and (ii) supplier 2 earns an expected profit of $\delta\left(\Pi_{2 L}-\Pi_{1 L}\right)+(1-\delta)\left(\Pi_{2 H}-\Pi_{1 H}\right)$, while supplier 1 earns zero profit.

Such an outcome can be achieved if the dominating supplier 2 bids a quantity-inflexible contract-2 $\theta$ with parameters $\left(\bar{q}_{2 \theta}, \Pi_{2 \theta}-\Pi_{1 \theta}\right)$ for $\theta \in\{H, L\}$, while the dominated supplier 1 bids quantity-inflexible contract- $1 \theta$ with parameters $\left(\bar{q}_{1 \theta}, 0\right)$ for $\theta \in\{H, L\}$. The two-part tariff buy-back contracts specified in the proposition also induce the retailer to order $\bar{q}_{i \theta}$ and ensures that $E\left[m_{i \theta}\left(\bar{q}_{i \theta}, D_{\theta}\right)\right]=0$ for $i=1$ and $E\left[m_{i \theta}\left(\bar{q}_{i \theta}, D_{\theta}\right)\right]=\Pi_{2 \theta}-\Pi_{1 \theta}$ for $i=2$.

We observe that the expected surplus of type- $\theta$ retailer who accepts contract- $2 L$ is $T_{2 \theta}(q)-$ $E\left[m_{2 L}\left(q, D_{\theta}\right)\right]=(1-\rho) t_{2 \theta}(q)$. As such, type- $\theta$ retailer would order $\bar{q}_{2 \theta}$ units regardless of whether he/she accepts contract-2L. Similarly, we observe that the expected surplus of type- $\theta$ 
retailer who accepts contract- $2 H$ is $T_{2 \theta}(q)-E\left[m_{2 L}\left(q, D_{\theta}\right)\right]=t_{2 \theta}(q)-\left(\Pi_{2 H}-\Pi_{1 H}+F\right)$. The type- $\theta$ retailer would order $\bar{q}_{2 \theta}$ units regardless whether he/she accepts contract- $2 H$.

Finally, we show that the proposed strategies are feasible for the omitted within-menu IC constraints for both suppliers. Consider supplier 2's omitted constraints and assume $\theta=L$. The left-hand side (LHS) of the within-menu IC constraint (IC) is

$$
\sup _{q \geq 0}\left\{T_{2 L}(q)-E\left[m_{2 L}\left(q, D_{L}\right)\right]\right\}=\sup _{q \geq 0}\left\{(1-\rho) t_{2 L}(q)\right\}=\frac{\Pi_{1 L}}{t_{2 L}\left(\bar{q}_{2 L}\right)} \cdot t_{2 L}\left(\bar{q}_{2 L}\right)=\Pi_{1 L}
$$

Similarly, the right hand side (RHS) is

$$
\sup _{q \geq 0}\left\{T_{2 L}(q)-E\left[m_{2 H}\left(q, D_{L}\right)\right]\right\}=T_{2 L}\left(\bar{q}_{2 L}\right)-\left(\Pi_{2 H}-\Pi_{1 H}\right)=\Pi_{2 L}-\left(\Pi_{2 H}-\Pi_{1 H}\right) .
$$

The LHS minus RHS of the within-menu IC constraint (IC) is $\Pi_{1 L}-\Pi_{2 L}+\left(\Pi_{2 h}-\Pi_{1 h}\right)$. According to part c) of Lemma $2, \Pi_{1 L}-\Pi_{2 L}+\Pi_{2 H}-\Pi_{1 H}>0$. Thus, the within-menu IC constraint (IC) is satisfied for $\theta=L$. When $\theta=H$, the LHS minus RHS of the within-menu IC constraint

(IC) is $\Pi_{1 H}-\frac{\Pi_{1 L}}{t_{2 L}\left(\bar{q}_{2 L}\right)} t_{2 H}\left(\bar{q}_{2 H}\right)=\Pi_{1 H}-\beta \Pi_{1 L}=\Pi_{1 H}-\Pi_{1 H}=0$. Using the same procedure, we find that with the proposed contracts, the omitted within-menu IC constraints of supplier 1 are satisfied for $\theta=H$ and $\theta=L$. This completes the proof of Proposition 2.

\section{Proof of Proposition 3}

According to Lemma 3, if the within-menu constraints are relaxed, supplier 1 makes an expected profit equal to $\delta\left(\Pi_{1 L}-\Pi_{2 L}\right)$ because $\Pi_{2 L}<\Pi_{1 L}$ and $\left(\Pi_{1 H}-\Pi_{2 H}\right)^{+}=0$ since $\Pi_{2 H} \geq \Pi_{1 H}$. On the other hand, supplier 2 makes an expected profit of $(1-\delta)\left(\Pi_{2 H}-\Pi_{1 H}\right)$. This result can be achieved if i) supplier 1 bids a quantity-inflexible contract- $1 L$ with parameters $\left(\bar{q}_{1 L}, \Pi_{1 L}-\right.$ $\left.\Pi_{2 L}\right)$ and a dummy contract- $1 H$ and ii) supplier 2 bids a dummy contract- $2 L$ and a quantityinflexible contract- $2 H$ with parameters $\left(\bar{q}_{2 H}, \Pi_{2 H}-\Pi_{1 H}\right)$. Next, we verify that the omitted within-menu IC constraints are satisfied. For $\theta=L$, the LHS of the omitted within-menu IC constraint (IC) is $T_{2 L}\left(\bar{q}_{2 L}\right)-\left(\Pi_{2 L}-\Pi_{1 L}\right)=\Pi_{1 L}$, while the RHS is $T_{2 L}\left(\bar{q}_{2 H}\right)-\left(\Pi_{2 H}-\Pi_{1 H}\right)<$ $T_{2 L}\left(\bar{q}_{2 L}\right)-\left(\Pi_{2 H}-\Pi_{1 H}\right)=\Pi_{2 L}-\left(\Pi_{2 H}-\Pi_{1 H}\right)$. According to part c) of Lemma $2, \Pi_{1 L}>$ $\Pi_{2 L}-\left(\Pi_{2 H}-\Pi_{1 H}\right)$. Hence, the omitted within-menu IC constraint is satisfied for $\theta=L$. Using 
a similar approach, we find that the omitted within-menu IC constraint is satisfied for $\theta=H$.

Similarly, it is easy to show that the two-part tariff buy-back contracts specified in the proposition induce the retailer to order the system optimal quantities $\bar{q}_{1 L}$ and $\bar{q}_{2 H}$, and thus ensure that $E\left[m_{1 L}\left(\bar{q}_{1 L}, D_{L}\right)\right]=\Pi_{1 L}-\Pi_{2 L}$ and $E\left[m_{2 H}\left(\bar{q}_{2 H}, D_{H}\right)\right]=\Pi_{2 H}-\Pi_{1 H}$.

It is important to point out that supplier 1 has no incentive to offer a distinctive contract$1 H$. We use contradiction to prove this claim. Assume that contract- $1 H$ is a distinctive contract that induces $\hat{q}_{1 H h}=q_{1 H}$ and gives supplier 1 an expected profit of $m_{1 H}=E\left[m_{1 H}\left(q_{1 H}, D_{H}\right)\right] \geq 0$. The between-menu IR constraint would require $T_{1 H}\left(q_{1 H}\right)-m_{1 H} \geq T_{2 H}\left(\bar{q}_{2 H}\right)-\left(\Pi_{2 H}-\Pi_{1 H}\right)=$ $\Pi_{1 H}$. Because $\Pi_{1 H}=\sup _{q \geq 0}\left\{T_{1 H}(q)\right\} \geq T_{1 H}\left(q_{1 H}\right)-m_{1 H}$, supplier 1 must make sure that $q_{1 H}=\bar{q}_{1 H}$ and $m_{1 H}=0$. This contract does not increase supplier 1's chance of winning the type- $H$ retailer's business because supplier 2 can win by slightly reducing the markup such that the RHS of the between-menu IR constraint is slightly greater than $\Pi_{1 H}$. However, the additional contract- $1 H$ could cannibalize contract- $1 L$. The within-menu IC constraint requires $T_{1 L}\left(\bar{q}_{1 L}\right)-\left(\Pi_{1 L}-\Pi_{2 L}\right)=\Pi_{2 L} \geq \sup _{q \geq 0}\left\{T_{1 L}(q)-E\left[m_{1 H}\left(q, D_{L}\right)\right]\right\}$.

Let type- $L$ retailer's best response to contract- $1 H$ be $q_{(1 H) L}$. The sign of $\Pi_{2 L}-T_{1 L}\left(q_{(1 H) L}\right)+$ $E\left[m_{1 H}\left(q_{(1 H) L}, D_{L}\right)\right]$ is indefinite. When it is positive, the addition of contract- $1 H$ on supplier 1 's menu does not improve supplier 1's profit because the type- $L$ retailer still prefers contract$1 L$. When it is negative, the type- $L$ retailer would switch to contract- $1 H$. By re-arranging the terms, we find that supplier 1's profit is $E\left[m_{1 H}\left(q_{(1 H) L}, D_{L}\right)\right] \leq T_{1 L}\left(q_{(1 H) L}\right)-\Pi_{2 L} \leq \Pi_{1 L}-\Pi_{2 L}$. Recall that the initial contract- $1 L$ gives supplier 1 an expected profit of $\Pi_{1 L}-\Pi_{2 L}$. We can conclude that supplier 1 should not offer a distinctive contract- $1 H$. Using the same procedure, one can verify that supplier 2 has no incentive to offer a distinctive contract- $2 L$.

\section{Proof of Proposition 4}

According to Lemma 3, if the within-menu IC constraints are relaxed, when $F_{3} \leq F<F_{4}$, the dominating supplier 1 would earn an expected profit equal to $\delta \Pi_{1 L}+(1-\delta)\left(\Pi_{1 H}-\Pi_{2 H}\right)$. To achieve this outcome, supplier 1 can bid the two-part tariff buy-back contracts $1 L$ and $1 H$ as specified in the proposition. It can be verified that both contracts induce the retailer to order 
the chain-optimal quantity. If the type- $L$ retailer takes contract- $1 L$, she earns an expected profit equal to $(1-\rho) t_{1 L}\left(\bar{q}_{1 L}\right)-(1-\rho) \Pi_{1 L}=0$. If the type- $L$ retailer switches to contract- $1 H$, she earns an expected profit equal to $t_{1 L}\left(\bar{q}_{1 L}\right)-\left(\Pi_{1 H}-\Pi_{2 H}\right)=\Pi_{1 L}-\left(\Pi_{1 H}-\Pi_{2 H}\right)$. Part c) of Lemma 2 indicates that $\Pi_{2 L}=0$ and $\Pi_{1 L}+\Pi_{2 H}-\Pi_{1 H} \leq 0$ when $F \geq F_{3}$. The omitted within-menu IC constraints of supplier 1 are thus satisfied for $\theta=L$. Next, consider $\theta=H$. If the type- $H$ retailer accepts contract- $1 H$, she obtains a surplus of $t_{1 H}\left(\bar{q}_{1 H}\right)-\left(\Pi_{1 H}-\Pi_{2 H}\right)=\Pi_{2 H}$. If the type- $H$ retailer switches to contract- $1 L$, she obtains a surplus of $(1-\rho) t_{1 H}\left(\bar{q}_{1 H}\right)-(1-\rho) \Pi_{1 L}=$ $\left(1-1+\frac{\Pi_{2 H}}{\Pi_{1 H}-\Pi_{1 L}}\right)\left(\Pi_{1 H}-\Pi_{1 L}\right)=\Pi_{2 H}$. Hence, the omitted within-menu IC constraints of supplier 1 is satisfied for $\theta=H$. On the other hand, supplier 2 offers a dummy contract- $2 L$ and a distinctive contract- $2 H$ with parameters $m_{2 h}(q, D)=0$. It is easy to verify that the omitted within-menu constraints of supplier 2 are also satisfied. This proves part a) of the Proposition.

When $F \geq F_{4}, \Pi_{2 H}=0$. It can be verified that by offering a one-size-fits-all two-part tariff buy-back contract with parameters $w=b=r$, and $K=0$, the dominating supplier 1 earns an expected profit equal to $\delta \Pi_{1 L}+(1-\delta) \Pi_{1 H}$. This proves part b) of the proposition.

\section{Proof of Proposition 5}

We need to compare supplier 1's single-contract solution $\left(\alpha_{1 L}=1\right.$ and $\left.\alpha_{1 H}=0\right)$, with supplier 1's two-contract solution $\left(\alpha_{1 L}=1\right.$ and $\left.\alpha_{1 H}=1\right)$, i.e., we need to to compare $\pi_{1}^{1}(F)=\delta\left(\Pi_{1 L}-\right.$ $\left.\Pi_{2 L}\right)$ with $\pi_{1}^{2}(F)$, where $\pi_{1}^{2}(F)$ denotes the flexible supplier's profit given that the solution specified in Lemma 4 is implemented when the efficient supplier's fixed cost is $F$, where $F_{2} \leq$ $F \leq F_{3}$. It can be verified that $\pi_{1}^{2}\left(F_{2}\right)<\pi_{1}^{1}\left(F_{2}\right)$, which implies that when $F=F_{2}$, offering two contracts is less profitable than offering one contract to attract the low-volume retailer.

The first derivatives of $\pi_{1}^{1}(F)$, and $\pi_{1}^{2}(F)$ with respect to $F$ depend on whether $F_{2}>\frac{\left(r-c_{2}\right)^{2}}{2 r}$. While we do not show the details here, it can be shown that $\frac{\partial \pi_{1}^{2}(F)}{\partial F}$ is no less than $\frac{\partial \pi_{1}^{1}(F)}{\partial F}$. In summary, we know that $\pi_{1}^{2}\left(F_{2}\right) \leq \pi_{1}^{1}\left(F_{2}\right)$. In addition, we know that when $F=F_{3}$, offering two coordinating contracts is optimal, i.e., $\pi_{1}^{2}\left(F_{3}\right) \geq \pi_{1}^{1}\left(F_{3}\right)$. Therefore, there exists a unique intercept, denoted by $F_{2}^{\prime}$, where $F_{2} \leq F_{2}^{\prime} \leq F_{3}$, such that $\pi_{1}^{2}\left(F_{2}^{\prime}\right)=\pi_{1}^{1}\left(F_{2}^{\prime}\right)$. To characterize $F_{2}^{\prime}$ we compare $\pi_{1}^{1}=\delta\left(\Pi_{1 L}-\Pi_{2 L}\right)$ with $\pi_{1}^{2}$ for each of the four cases in Lemma 4, where 
$\pi_{1}^{2}$ is computed by plugging the optimal contract parameters into the flexible supplier's profit function. Also, $\pi_{1}^{1}$ has two cases, $\pi_{1}^{1}=\delta\left(\Pi_{1 L}-\Pi_{2 L}\right)$ if $F<\frac{\left(r-c_{2}\right)^{2}}{2 r}$ and $\pi_{1}^{1}=\delta \Pi_{1 L}$ otherwise.

Case 1a: This case requires $\frac{r-c_{2}}{c_{1}-c_{2}} \geq \frac{(1-\delta) \beta}{\delta(\beta-1)}$ and $F_{2} \leq F \leq \frac{\left(r-c_{2}\right)^{2}}{2 r}$. So we know that $\pi_{1}^{1}=$ $\delta\left(\Pi_{1 L}-\Pi_{2 L}\right)$. Using part 1a of Lemma 4 , we can write $\pi_{1}^{2}=\delta\left(\Pi_{1 L}-\Pi_{2 L}\right)+(1-\delta) \beta\left(c_{2}-\right.$ $\left.c_{1}\right) \frac{r-c_{2}}{r}+(1-\delta) F$. Thus, $\pi_{1}^{2}>\pi_{1}^{1}$ when $(1-\delta) \beta\left(c_{2}-c_{1}\right) \frac{r-c_{2}}{r}+(1-\delta) F>0$. Solving for $F$ we find that $\pi_{1}^{2}>\pi_{1}^{1}$ when $F>\frac{\beta\left(c_{1}-c_{2}\right)\left(r-c_{2}\right)}{r}$. Thus, the relevant threshold is $F_{2(1 a)}^{\prime}=\frac{\beta\left(c_{1}-c_{2}\right)\left(r-c_{2}\right)}{r}$. We can then verify that $F_{2(1 a)}^{\prime} \geq F_{2}$. We also need to check whether $F_{2(1 a)}^{\prime} \leq \frac{\left(r-c_{2}\right)^{2}}{2 r}$. This may or may not hold. Therefore, if $F_{2(1 a)}^{\prime} \leq \frac{\left(r-c_{2}\right)^{2}}{2 r}, F_{2}^{\prime}=F_{2(1 a)}^{\prime}$ and $F_{2} \leq F_{2}^{\prime} \leq \frac{\left(r-c_{2}\right)^{2}}{2 r} \leq F_{3}$. Thus, we conclude that for $F_{2} \leq F<F_{2}^{\prime}$ a single contract attracting the low-volume retailer is optimal; if $F_{2}^{\prime} \leq F<\frac{\left(r-c_{2}\right)^{2}}{2 r}$ the two contract solution in part 1a of Lemma 4 is optimal; and if $\frac{\left(r-c_{2}\right)^{2}}{2 r} \leq F \leq F_{3}$ the two contract solution in part 1b of Lemma 4 is optimal.

Case 1b: If $\frac{r-c_{2}}{c_{1}-c_{2}} \geq \frac{(1-\delta) \beta}{\delta(\beta-1)}$ and $F_{2(1 a)}^{\prime}>\frac{\left(r-c_{2}\right)^{2}}{2 r}$, the point at which $\pi_{1}^{1}$ and $\pi_{1}^{2}$ intersect must belong to case $1 \mathrm{~b}$ of Lemma 4 . In this case, $\pi_{1}^{1}=\delta \Pi_{1 L}$. In addition $\pi_{1}^{2}$ can be computed using part $1 \mathrm{~b}$ of Lemma 4 . The threshold where these curves intersect is computed by solving $\pi_{1}^{1}=\pi_{1}^{2}$. This threshold exists and is unique since there is a unique crossing point between $\pi_{1}^{1}$ and $\pi_{1}^{2}$ for $F_{2} \leq F \leq F_{3}$. The threshold is $F_{2(1 b)}^{\prime}=\frac{\beta\left[(2 \beta-1)^{2}\left(2 r-c_{1}-c_{2}\right)\left(c_{1}-c_{2}\right)+\left(r-c_{1}\right)^{2}\right]}{2 r(2 \beta-1)^{2}}$. We conclude that the cut-off point is $F_{2}^{\prime}=F_{2(1 b)}^{\prime}$, which satisfies $F_{2} \leq \frac{\left(r-c_{2}\right)^{2}}{2 r} \leq F_{2}^{\prime} \leq F_{3}$. Thus, we have that for $F_{2} \leq F<F_{2}^{\prime}$, a single contract attracting the low-volume retailer is optimal; and if $F_{2}^{\prime} \leq F \leq F_{3}$ the two contract solution provided in part 1 b of Lemma 4 is optimal.

Case 2a: This case requires $\frac{r-c_{2}}{c_{1}-c_{2}}<\frac{(1-\delta) \beta}{\delta(\beta-1)}$ and $F_{2} \leq F \leq F_{3}^{\prime}$, where $F_{3}^{\prime}>\frac{\left(r-c_{2}\right)^{2}}{2 r}$. There are two subcases: (i) If $F \leq \frac{\left(r-c_{2}\right)^{2}}{2 r}$, we have $\pi_{1}^{1}=\delta\left(\Pi_{1 L}-\Pi_{2 L}\right)$ and (ii) If $F>\frac{\left(r-c_{2}\right)^{2}}{2 r}$, we have $\pi_{1}^{1}=\delta \Pi_{1 L}$. In either case, $\pi_{1}^{2}$ is computed using part 2 a of Lemma 4 . For each case, the associated threshold can then be computed by solving $\pi_{1}^{1}=\pi_{1}^{2}$. For case (i) we obtain the following threshold:

$F_{2(i)}^{\prime}=\frac{\left[r^{2}(\beta-1)^{2} \delta^{2}(\delta+\beta(3-4 \delta))+\beta^{2}(1-\delta)^{2}(3 \delta+\beta(1-4 \delta))\left(2 r-c_{1}\right) c_{1}-c_{2}\left(2 r-c_{2}\right)(\beta+\delta-2 \beta \delta)^{3}\right]}{2 r(1-\delta)(\beta+\delta-2 \beta \delta)^{2}}$,

while for case (ii) we obtain $F_{2(i i)}^{\prime}=\frac{\beta\left[\left(2 r-c_{1}-c_{2}\right)\left(c_{1}-c_{2}\right)(\beta+\delta-2 \beta \delta)+\delta(1-\beta \delta)\left(r-c_{1}\right)^{2}\right]}{2 r(\beta+\delta-2 \beta \delta)}$. If $F_{2(i)}^{\prime} \leq \frac{\left(r-c_{2}\right)^{2}}{2 r}$, then $F_{2}^{\prime}=F_{2(i)}^{\prime}$. If $F_{2(i)}^{\prime}>\frac{\left(r-c_{2}\right)^{2}}{2 r}$, then we consider case (ii). If $F_{2(i i)}^{\prime}<F_{3}^{\prime}$ then $F_{2}^{\prime}=F_{2(i i)}^{\prime}$. If 
$F_{2(i i)}^{\prime}>F_{3}^{\prime}$, then the threshold $F_{2}^{\prime}$ must be found by considering case $2 \mathrm{~b}$.

Case 2b: This case requires $\frac{r-c_{2}}{c_{1}-c_{2}}<\frac{(1-\delta) \beta}{\delta(\beta-1)}$ and $F_{3}^{\prime} \leq F \leq F_{3}$, where $F_{3}^{\prime}>\frac{\left(r-c_{2}\right)^{2}}{2 r}$. We have $\pi_{1}^{1}=\delta \Pi_{1 L}$, while $\pi_{1}^{2}$ can be computed using part $2 \mathrm{~b}$ of Lemma 4 . The threshold is computed by solving $\pi_{1}^{1}=\pi_{1}^{2}$. We obtain the threshold $F_{2(2 b)}^{\prime}=\frac{\beta\left((2 \beta-1)^{2}\left(2 r-c_{1}-c_{2}\right)\left(c_{1}-c_{2}\right)+\left(r-c_{1}\right)^{2}\right)}{2 r(2 \beta-1)^{2}}$. If the threshold does not belong to case 2a, i.e., if $F_{2(i)}^{\prime}>\frac{\left(r-c_{2}\right)^{2}}{2 r}$ and $F_{2(i i)}^{\prime}>F_{3}^{\prime}$, then $F_{2}^{\prime}=F_{2(2 b)}^{\prime}$. We conclude that for case 2 there are two possibilities. If case 2 a contains the threshold, then for $F_{2} \leq F<F_{2}^{\prime}$, a single contract attracting the low-volume retailer is optimal; if $F_{2}^{\prime} \leq F \leq F_{3}^{\prime}$ the two contract solution provided in part $2 \mathrm{a}$ of Lemma 4 is optimal; and if $F_{3}^{\prime} \leq F \leq F_{3}$ the two contract solution provided in part $2 \mathrm{~b}$ of Lemma 4 is optimal. If case $2 \mathrm{~b}$ contains the threshold, then for $F_{2} \leq F<F_{2}^{\prime}$, a single contract attracting the low-volume retailer is optimal; and if $F_{2}^{\prime} \leq F \leq F_{3}$ the two contract solution provided in part $2 \mathrm{~b}$ of Lemma 4 is optimal.

Finally, we identify the best response of the dominated supplier 2. If supplier 1 offers two contracts, supplier 2 cannot match them. If supplier 2 does not bid, supplier 1 can increase the markup of each contract. This could give the opportunity to supplier 2 to win the business. A stable equilibrium is then supplier 1 does not increase the markup (bidding the contracts in Lemma 4) and supplier 2 bids a zero markup contract $\left(w_{2}=c_{2}, b_{2}=0\right.$, and $\left.K_{2}=F\right)$.

When $F_{2}<F<F_{2}^{\prime}$, the dominating supplier 1 opts to exclude the high-volume retailer. Supplier 2 can now increase the markup of its contract. Initially, supplier 2 offers a universal (to both retailer types) contract with $w_{2}=c_{2}$ and $K_{2}=F$. Supplier 2 can increase $K_{2}$ to $K_{2}+\Delta_{m}$, where $\Delta_{m}$ is non-negative. This will affect the between-menu IR constraints of supplier 1. Note that both retailer types can switch to this new universal contract. To counter this new contract, supplier 1 (if it offers two contracts) can just increase the fixed charge to $K_{1}+\Delta_{m}$. The within-menu and between-menu constraints will be satisfied. Supplier 1's profit by offering two contracts increases from $\pi_{1}^{2}(F)$ to $\pi_{1}^{2}(F)+\Delta_{m}$. Supplier 1 needs to compare this option with the one-contract solution. By offering contract- $1 L$ only, the supplier 1's profit is $\pi_{1}^{1}(F)$. If $\pi_{1}^{2}(F)+\Delta_{m}>\pi_{1}^{1}(F)$, i.e., if $\Delta_{m}>\pi_{1}^{1}(F)-\pi_{1}^{2}(F)$, then supplier 1 will offer two contracts. Therefore, to ensure that the flexible supplier only offers contract- $1 L$, the dominated efficient supplier cannot increase the fixed charge $K_{2}$ by more than $\pi_{1}^{1}(F)-\pi_{1}^{1}(F)$. 


\section{University Library}

\section{- M M I N E R VA A gateway to Melbourne's research publications}

Minerva Access is the Institutional Repository of The University of Melbourne

Author/s:

Li, Z;Ryan, JK;Shao, L;Sun, D

Title:

Supply Contract Design for Competing Heterogeneous Suppliers under Asymmetric Information

Date:

2015

Citation:

Li, Z., Ryan, J. K., Shao, L. \& Sun, D. (2015). Supply Contract Design for Competing Heterogeneous Suppliers under Asymmetric Information. Production and Operations Management, 24 (5), pp.791-807. https://doi.org/10.1111/poms.12294.

Persistent Link:

http://hdl.handle.net/11343/116302 